\title{
Thermal infrared remote sensing of mineral dust over land and ocean: a spectral SVD based retrieval approach for IASI
}

\author{
L. Klüser ${ }^{1,2}$, D. Martynenko ${ }^{1}$, and T. Holzer-Popp ${ }^{1}$ \\ ${ }^{1}$ German Aerospace Center (DLR), German Remote Sensing Datacenter (DFD), 82334 Wessling, Germany \\ ${ }^{2}$ University of Augsburg, Institute of Physics, 86135 Augsburg, Germany
}

Received: 13 December 2010 - Published in Atmos. Meas. Tech. Discuss.: 21 January 2011

Revised: 13 April 2011 - Accepted: 28 April 2011 - Published: 2 May 2011

\begin{abstract}
From the high spectral resolution thermal infrared observations of the Infrared Atmospheric Sounding Interferometer (IASI) mineral dust AOD (transferred from thermal infrared to $0.5 \mu \mathrm{m}$ ) is retrieved using a Singular Vector Decomposition of brightness temperature spectra. As infrared retrieval based on $8-12 \mu \mathrm{m}$ observations, dust observation with IASI is independent from solar illumination. Through the linear combinations of suitable independent singular vectors weighted by their contribution to the observed signal, and a projection of different a-priori dust spectra on the resulting signal the dust can be well distinguished from the influence of surface emissivity and gas absorption. In contrast to lookup-table based single-channel retrievals this method takes advantage of the spectral shape of dust extinction and surface and atmosphere influence over the total 8-12 $\mu \mathrm{m}$ window band. Using different a-priori spectra for dust extinction allows also for an estimation of dust particle size in terms of effective radius based on the respective dust model size distributions. These dust models are also used for the transfer of infrared AOD to $0.5 \mu \mathrm{m}$.

Four months of IASI observations covering Northern Africa and Arabia are used for evaluation. Two large scale dust events, one covering the Arabian Peninsula and adjacent parts of the Indian Ocean, the other over the Atlantic Ocean off the coast of West-Africa, are analysed and compared with other satellite images. They also show the good suitability of IASI data for dust observation at day and night. Monthly means derived from IASI observations represent well the known seasonal cycles of dust activity over Northern Africa and Arabia. IASI Dust $\mathrm{AOD}_{0.5 \mu \mathrm{m}}$ and AERONET coarse mode $\mathrm{AOD}_{0.5 \mu \mathrm{m}}$ are reasonably well (linearly) corre-
\end{abstract}

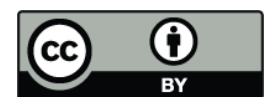

Correspondence to: L. Klüser (lars.klueser@dlr.de) lated with $\rho=0.623$. Moreover, comparison of time series of AERONET and IASI observations shows that the evolution of dust events is very well covered by the IASI observations. Rank correlation between dust effective radius and AERONET Ångström exponent is -0.557 indicating the general capability of (qualitative) dust particle size information being provided by this method.

\section{Introduction}

Airborne mineral dust plays an important role in the climate system as it has several effects which directly or indirectly impact on the atmospheric state and climate. It reduces surface insolation by extinction of solar radiation (King et al., 1999; Slingo et al., 2006), which is of importance not only for climate and atmospheric processes, but also for solar energy applications (Breitkreuz et al., 2007). By the same means, airborne dust can heat the atmospheric layer due to absorption of solar radiation (Shenk and Curran, 1974; King et al., 1999; Dunion and Velden, 2004). Moreover airborne mineral dust has effects on cloud microphysics (Mahowald and Kiehl, 2003; Ansmann et al., 2008; Klüser and Holzer-Popp, 2010) and precipitation (N'Tchayi Mbourou et al., 1997; Rosenfeld et al., 2001; Hui et al., 2008). When being transported over the Atlantic ocean, airborne dust from Northern Africa can also interact with tropical storms, affecting e.g. their strength and precipitation (Dunion and Velden, 2004; Evan et al., 2006a; Jenkins et al., 2008) and is a major source of iron input into the ocean (Jickells et al., 2005; Mahowald et al., 2005) and for the Amazonia rainforest (Koren et al., 2006). Airborne dust activity follows diurnal and seasonal cycles and has a very high spatial variability over Northern Africa and Arabia (Engelstaedter et al., 2006). 
Table 1. IASI and AIRS instrument characteristics, resolutions and stability (Aumann et al., 2003; Blumstein et al., 2004; Larar et al., 2010).

\begin{tabular}{llllll}
\hline & nadir ground resolution & swath & channels & spectral resolution & instrument stability \\
\hline IASI & $12 \mathrm{~km}$ & $48.3^{\circ}$ & 8461 & $0.5 \mathrm{~cm}^{-1}$ (apodised) & $0.1 \mathrm{~K}$ \\
\hline \multirow{2}{*}{ AIRS } & $13.5 \mathrm{~km}$ & $49.5^{\circ}$ & 2378 & $\frac{\lambda}{\delta \lambda}=1200\left(0.83 \mathrm{~cm}^{-1}\right.$ at $\left.10 \mu \mathrm{m}\right)$ & $0.2 \mathrm{~K}$ \\
\hline
\end{tabular}

Satellite remote sensing of dust is quite well established over dark surfaces such as ocean areas (King et al., 1999; Evan et al., 2006b) or vegetated surfaces (Kokhanovski and de Leeuw, 2009), where also aerosol type speciation is generally possible (Holzer-Popp et al., 2008). But over desert regions with bright reflecting surfaces many traditional aerosol retrieval algorithms cannot detect airborne dust. Efforts have been made to improve remote sensing capabilities over bright surfaces, e.g., the Absorbing Aerosol Index AAI (Torres et al., 1998) or the "Deep Blue" Algorithm for the MODerate resolution Imaging Spectro-radiometer MODIS (Hsu et al., 2004, 2006). The Multi-angle Imaging SpectroRadiometer (MISR) provides the potential to use multi-angle observations for aerosol retrievals, which also can be used to determine surface reflectance and thus to retrieve aerosol properties also over desert surfaces (Diner et al., 2005; Kahn et al., 2005; Kalashnikova et al., 2005). These algorithms can detect aerosol also over deserts, but they are not capable of a reliable aerosol type separation.

Due to large particle sizes and rather high absorption mineral dust can also be detected in the thermal infrared (TIR) range (Shenk and Curran, 1974; Ackerman, 1997). Different methods based either on temporal comparison of brightness temperatures (Legrand et al., 2001; Miller et al., 2008), on brightness temperature differences (Dunion and Velden, 2004; Chaboureau et al., 2007; Schepanski et al., 2007) or combinations of both (Li et al., 2007; Klüser and Schepanski, 2009) have been expolited successfully for dust remote sensing from geostationary satellites TIR instruments. For polar orbiting satellites a brightness temperature difference approach has been applied to MODIS observations over Asia by Zhang et al. (2006) for dust storm classification. Moreover the Atmospheric InfraRed Sounder AIRS provides a high number of spectral bands which is suitable for remote sensing of dust Aerosol Optical Depth (AOD), particle size and height information over ocean (Pierangelo et al., 2004, 2005; DeSouza-Machado et al., 2010; Peyridieu et al., 2010).

The Infrared Atmospheric Sounding Interferometer IASI flown on the METOP satellites has an even better spectral resolution (Blumstein et al., 2004; Larar et al., 2010) than AIRS and also a better spatial resolution of observations (see Table 1 for a comparison of instrument characteristics). Thus this instrument is very well suited for remote sensing of airborne dust from thermal infrared observations.
Over land surface emissivity with its high variability for desert soils is one critical parameter for dust remote sensing with thermal infrared methods (Shenk and Curran, 1974; Ackerman, 1997; Ogawa et al., 2003; Pierangelo et al., 2004; Klüser and Schepanski, 2009). Recently efforts have been made to compile a global database of surface emissivity (see e.g. Seemann et al., 2008). Any approach of direct radiative transfer modelling for AOD retrieval in the TIR spectrum over land requires sufficient information (or assumptions) on surface emissivity and land surface temperature, as otherwise the modelling of radiances will imply very high uncertainty due to background errors. Moreover radiative transfer modelling of dust effects on TIR radiance requires reliable estimation of the atmospheric state, i.e. temperature and humidity profiles. These must either be retrieved simultaneously with the dust properties or have to be known a priori.

The presented algorithm is designed to allow for fast dust remote sensing not only over ocean and vegetation, but also over arid land surfaces. Moreover it is intended to avoid a priori assumptions as far as possbile.

One approach for reduction of required a priori information is using a Singular Vector Decomposition (SVD, e.g., Rodgers, 2000) of observed spectra in order extract useful independent pieces of information. SVD separates the observed spectra into different modes of co-variability. Thus the strongest signal (being surface emissivity) will be contained in one or more singular vectors representing the highest amount of co-variability (leading singular vectors). Such an approach is used here for detecting the mineral dust signal within observed IASI spectra.

After a short overview over the basic theory behind singular vector decomposition in Sect. 2, the retrieval method is described in Sect. 3 whereas Sect. 4 presents results and evaluation. After a discussion of strengths and limitations of the retrieval method in Sect. 5 conclusions are drawn in Sect. 6.

\section{Basic principles of singular vector decomposition}

Principal component analysis (PCA) is a general term for methods, which aim at separating data fields into different uncorrelated signals, the principal components of the system. They can be used for reducing the dimensionality of a problem and for finding different uncorrelated modes (components) which describe the data (Rodgers, 2000). 
PCA is a classical tool from statistical methods to explore the extraction of the uncorrelated and independent variables and concentrate attention only on main (principal) components which should be retrieved. Such an approach has advantages (in comparison with, for example, Factor-analysis) and is useful since it will give in an unbiased way both the number of parameters that can be retrieved and their interpretation.

Good overviews over the basic theory of PCA with respect to radiance spectra (as e.g., from IASI) are given in Matricardi (2010) as well as in Rodgers (2000). Classical principal component theory consists of solving the Eigenvalue problem of the covariance matrix of any data $n \times m$ matrix $\mathbf{X}$ formed by $n$ data vectors (e.g., observations) $\mathbf{x}$ of dimension $m$. If A denotes the $m \times m$ matrix formed by the $m$ Eigenvectors (sorted in ascending order with respect to the magnitude of the corresponding Eigenvalues), the vector of principal components (or PC weights), $\mathbf{y}$ is given by

$\mathbf{y}=\mathbf{A x}$

(Matricardi, 2010). From the knowledge of $\mathbf{A}$ and the respective $\mathbf{y}$ any observation $\mathbf{x}$ can be reconstructed by

$\mathbf{x}=\mathbf{A}^{\mathrm{T}} \mathbf{y}$

If the elements of $\mathbf{x}$ are correlated, a number $k<m$ of Eigenvectors contained in $\mathbf{A}$ is sufficient to reconstruct $\mathbf{x}$, hence a reduction of dimensionality is achieved (Matricardi, 2010). The possible magnitude of dimension reduction depends on the desired level of accuracy of the reconstructed field.

As $\mathbf{A x}$ has a dimension different from that of $\mathbf{y}$ in the case of a non-symmetric field, a Singular Vector Decomposition (SVD) can be regarded mathematically as solving an equivalent to the Eigenvalue problem of non-symmetric fields (Rodgers, 2000). Thus SVD can be seen as principal component analysis of the original data matrix instead of the covariance matrix. For a non-symmetric $n \times m$ data matrix $\mathbf{X}$, a singular vector decomposition is solving the equation

$\mathbf{X}=\mathbf{U} \wedge \mathbf{V}^{\mathrm{T}}$

where $\Lambda$ is the diagonal $n \times n$ array of singular values $\Lambda_{i}$. $\mathbf{U}$ is the $m \times m$ matrix of left-singular vectors and $\mathbf{V}$ is the $n \times n$ matrix of right-singular vectors. The left- and the rightsingular vectors are basis vectors for the observation space $\mathbf{M}$, which includes, in particular, the observation data matrix $\mathbf{X}$, respectively. The observation matrix $\mathbf{X}$ is normalized such that the euclidian norm of the singular vectors is unity and singular values are also normalized.

SVD is applied to the observation field directly and the corresponding Singular Vectors (SV) form a basis of the observation space - without any statistical transformation (like correlation or covariance) being necessary. Thus weights of the singular vectors (similar to the Eigenvectors in classical PCA) can directly be used to reconstruct the observation (spectrum) as a linear combination of the singular vectors.

\section{Retrieval method}

\subsection{Filtering of IASI data}

Mineral dust is generally characterised by high extinction around $9.5 \mu \mathrm{m}$ and much lower extinction at wavelengths around $8 \mu \mathrm{m}$ and around $12 \mu \mathrm{m}$ (e.g., Volz, 1973; Ackerman, 1997; DeSouza-Machado et al., 2010). The exact shape of the extinction spectrum is subject to the mineral composition and the size distribution of the dust. As the well known generally v-shaped extinction curve of mineral dust (largely due to absorption: Volz, 1973; Takashima and Masuda, 1987; DeSouza-Machado et al., 2010) is very characteristic in the $8-12 \mu \mathrm{m}$ region (TIR window), the high spectral sampling of IASI can be exploited to avoid gas absorption lines in this region and consequently to obtain mineral dust properties from the observed radiance spectra. Brightness temperatures between $8 \mu \mathrm{m}$ and $12 \mu \mathrm{m}$ are collected into 42 bins (equidistant in wavenumber space), thus 420 IASI channels are used for the retrieval. Although the wavenumber coordinate is used for collecting IASI observation into the filtered spectrum (as it is the spectral coordinate of the IASI observations), we use wavelength as spectral coordinate in subsequent parts of the paper, as this is the notation mainly used for thermal infrared dust studies. For the readers orientation, $8 \mu \mathrm{m}$ wavelength translates into a wavenumber of $1250 \mathrm{~cm}^{-1}, 10 \mu \mathrm{m}$ relate to $1000 \mathrm{~cm}^{-1}$ and $12 \mu \mathrm{m}$ equals $833.33 \mathrm{~cm}^{-1}$. The brightness temperature used for each of the 42 bins is represented by the maximum brightness temperature of the 10 respective channel values observed within each bin, reducing the effects of narrow gas absorption lines onto the dust retrieval. Many gas absorption features can be eliminated by this way, but of course broad band features such as ozone absorption around $9.6 \mu \mathrm{m}$ and the water vapour continuum cannot be avoided and remain part of the filtered spectra.

From the filtered 8-12 $\mu \mathrm{m}$ spectrum the "baseline" temperature $\left(T_{\text {base }}\right)$ is determined as its overall maximum brightness temperature.

As indicated in the flowchart in Fig. 1, the next step is a partial cloud filtering of observations, flagging pixels with high clouds or inhomogeneous scenes. Thus as a first step a temperature threshold is applied for the baseline temperature $T_{\text {base }}$. Observations with $T_{\text {base }}$ lower than $240 \mathrm{~K}$ are assumed to represent high level clouds and thus being inappropriate for dust retrieval. This threshold is inspired by the ice cloud threshold of $238 \mathrm{~K}$ e.g. reported in Chylek et al. (2006). The Integrated Imaging Subsystem (IIS) of the IASI instrument is exploited to obtain the spatial homogeneity within one IASI pixel. In contrast to e.g., cumulus clouds, mineral dust is characterised by rather high spatial homogeneity (Evan et al., 2006b), moreover thermally very inhomogeneous conditions within one field-of-view (FOV) can largely influence the radiance spectrum observed by the IASI instrument. Only if the variance of IIS brightness temperatures ( $\sigma^{2}$ (IIS)) for the respective IASI spectrometer observation is sufficiently low 


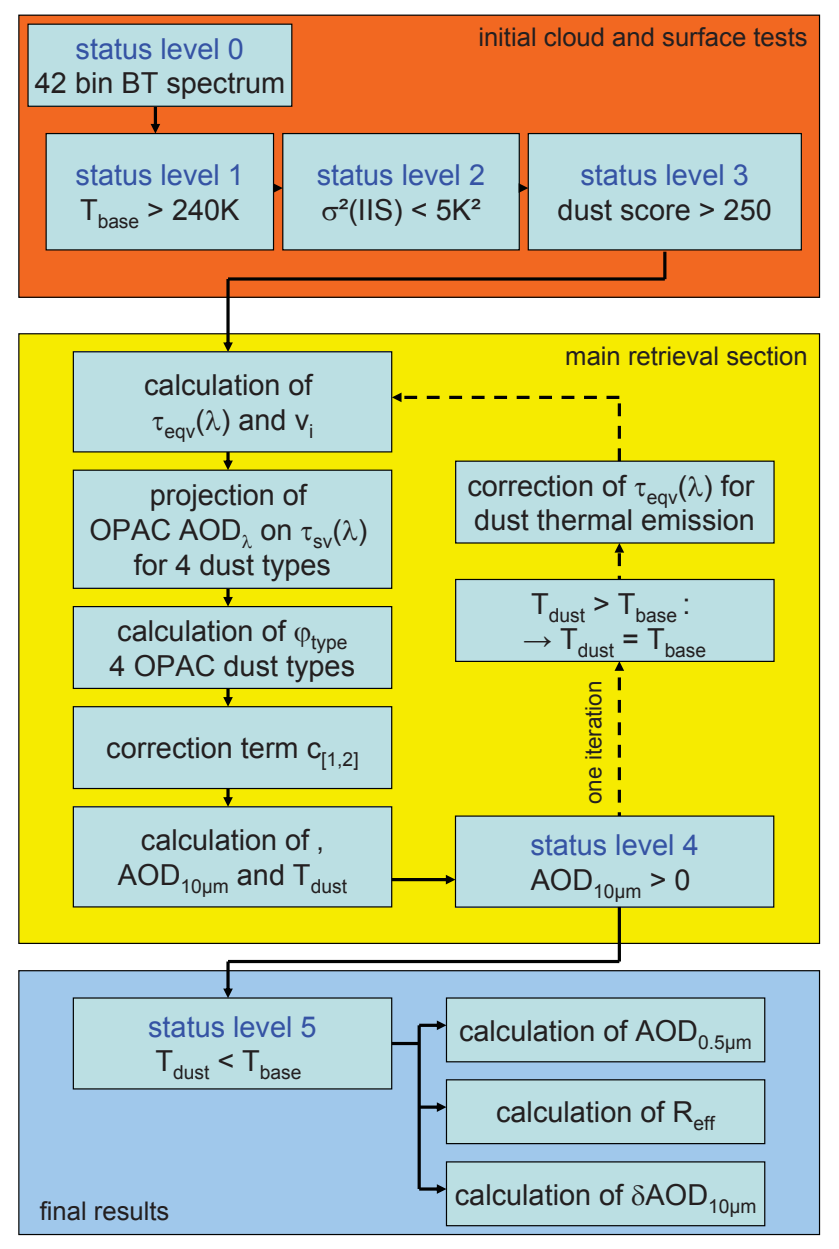

Fig. 1. Algorithm flowchart of the consecutive steps performed in the IASI dust retrieval. The status level provides an additional information about which step or test failed when no dust AOD is retrieved.

$\left(<4 \mathrm{~K}^{2}\right)$, the pixel is passed on to the dust retrieval (retrieval status levels 1 and 2, respectively, see Fig. 1). This filtering approach flags out cirrus clouds and inhomogeneous scenes in which it is not clear from which surface the IASI signal emerges. Homogeneous low level clouds like e.g. stratocumulus are not filtered out allowing for dust retrieval above them.

Brightness temperature spectra then are transformed into a spectrum of a quantity $\tau_{\text {eqv }}(\lambda)$, which can be regarded as an "equivalent optical depth". The calculation of $\tau_{\text {eqv }}$ follows the very simple approach of

$$
L_{\mathrm{obs}}(\lambda)=e^{-\tau_{\mathrm{eqv}}(\lambda) / \cos \left(\Theta_{\mathrm{v}}\right)} B_{\lambda}\left(T_{\text {base }}\right)
$$

where $L_{\mathrm{obs}}(\lambda)$ denotes the radiance obtained from the binned maximum brightness temperature spectrum and $\Theta_{\mathrm{v}}$ is the viewing zenith angle (see e.g., Ackerman, 1997; Thomas et al., 2009). $\tau_{\text {eqv }}$ still contains significant pieces of information about surface emissivity. Especially in the traditional
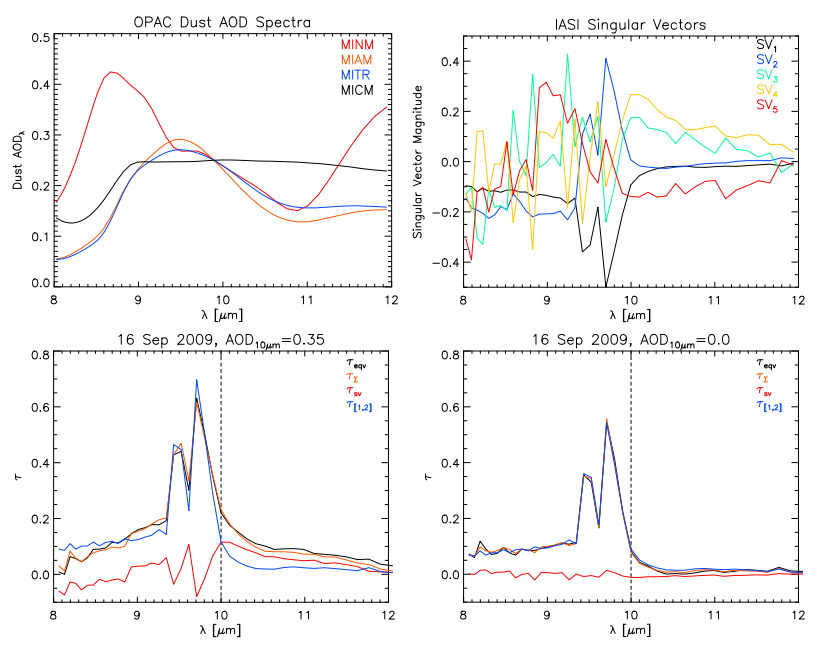

Fig. 2. Dust AOD spectra for four dust types from the OPAC database (top left), leading five singular vectors obtained from IASI observations (top right) and example spectra of different retrieval steps for dust (bottom left) and dust free (bottom right) observations. The positions of the example observations are indicated by the arrows in the bottom right image of Fig. 3.

"split-window" region between $10 \mu \mathrm{m}$ and $12 \mu \mathrm{m}$ the signals of desert soil emissivity and mineral dust extinction are quite similar (see Fig. 2). Also e.g., the ozone optical depth peaking around $9.6 \mu \mathrm{m}$ and the influence of the water wapour continuum contribute to $\tau_{\text {eqv }}$.

Table 2 provides a set of rather simple tests probing the $\tau_{\text {eqv }}$ spectrum for the typical dust v-shape (Volz, 1973; Hess et al., 1998) which can also be seen in the OPAC spectra and in the example spectra depicted in Fig. 2. These tests are generally rather arbitrarily motivated by the spectral shape of dust extinction and byvisual inspections of possible $\tau_{\text {eqv }}$ ratios providing information about dust. They are weak enough to allow for additional surface emissivity effects (Ogawa et al., 2003) to also pass the tests. If the score (sum of all positive tests) is larger than 250 , the FOV is passed on to further processing (retrieval status level 3). The threshold of 250 is rather conservative allowing for a lot of pixels to be passed on (see observations with retrieval being initiated and resulting sucessful retrievals in Fig. 3). In contrast to e.g., Evan et al. (2006b) or DeSouza-Machado et al. (2010) this scoring scheme does not represent a dust flag, i.e., FOVs with scores higher than 250 can also be dust free (see observations without dust detection in Fig. 3).

\subsection{Dust optical properties}

AOD spectra for four different dust mixtures from the Optical Properties of Aerosol and Clouds (OPAC) database (Hess et al., 1998) between $8 \mu \mathrm{m}$ and $12 \mu \mathrm{m}$ are used for dust characterisation in this method. Only a few other databases of TIR optical properties for mineral dust are available, e.g., from 
Table 2. FOV dust likelihood score test, the final score is the sum of the scores of all positive tests. Only FOVs with scores higher than 250 are used for dust retrieval. $\lambda_{x}$ denotes the wavelength corresponding to the maximum brightness temperature $\left(T_{\text {base }}\right)$.

\begin{tabular}{llr}
\hline Test no. & Test condition & Score \\
\hline 1 & $\tau_{\text {eqv }}(10.00 \mu \mathrm{m}) / \tau_{\text {eqv }}(10.63 \mu \mathrm{m})>2$ & 128 \\
2 & $\tau_{\text {eqv }}(10.10 \mu \mathrm{m}) / \tau_{\text {eqv }}(10.87 \mu \mathrm{m})>1$ & 64 \\
3 & $\tau_{\text {eqv }}(10.10 \mu \mathrm{m}) / \tau_{\text {eqv }}(11.49 \mu \mathrm{m})>1$ & 64 \\
4 & $\left(\lambda_{x}>11 \mu \mathrm{m}\right.$ or $\left.\lambda_{x}<9 \mu \mathrm{m}\right)$ and $\tau_{\text {eqv }}(10.10 \mu \mathrm{m}) / \tau_{\text {eqv }}(11.49 \mu \mathrm{m})>2$ & 64 \\
\hline
\end{tabular}

Volz (1973), Fouquart et al. (1987), Sokolik et al. (1998) or Dufresne et al. (2002), which moreover are (partly) based on each other or on the same dust samples. The general spectral shape of airborne mineral dust extinction in the TIR is rather similar between all of them as they all are based on the same dust mineralogy. The different spectral characteristics are the result of Mie calculations with identical refractive indices of mineral aerosol components after shifting the particle size distributions (Hess et al., 1998). The original OPAC dust type "mineral coarse mode" (MICM) cannot be used for this kind of retrieval as the spectral shape especially in the $10-12 \mu \mathrm{m}$ range is quite similar to the extinction spectrum of water vapour in this region and thus the retrieval has shown to be sensitive to water vapour when including the MICM type. Thus the OPAC dust mixtures used here are MINM, MIAM and MITR representing nucleation, accumulation and transportation modes of dust size distributions, respectively. As the original OPAC coarse mode dust (MICM) cannot be used for retrieval, an additional mixture of $25 \%$ MICM and $75 \%$ MITR is assumed to represent airborne coarse mode dust near source regions.

Figure 2 (left) shows AOD spectra of MIAM, MINM, MITR and MICM from OPAC (all scaled to $\mathrm{AOD}_{10 \mu \mathrm{m}}=0.25$ ). It is evident that MITR, MIAM and MINM spectra all have spectral shapes with a major peak around $9.5-10 \mu \mathrm{m}$ and minima at lower and higher wavelengths. This spectral shape of dust AOD is also reported reported in the spectral database of Volz (1973). MICM does not have such a strong characteristical dust peak, generally the spectral shape of MICM is much more different from the other dust types (and also from the observations) then those to each other.

The differences between the different dust modes may lead to information about the particle size in the projection of the observed spectra. Unfortunately all OPAC aerosol classes assume monomodal lognormal-type number size distributions, whereas dust aerosol in nature often shows bi-modal size distributions (see e.g., Chen et al., 2010). Moreover the Mie calculations as used in OPAC may be insufficient in TIR due to non-shericity effects. Brindley and Ignatov (2006) report strong effects of non-sphericity for scattering of solar reflection by coarse mode dust, Meland et al. (2010) show the effect of non-sphericity on TIR optical properties. A fixed min-
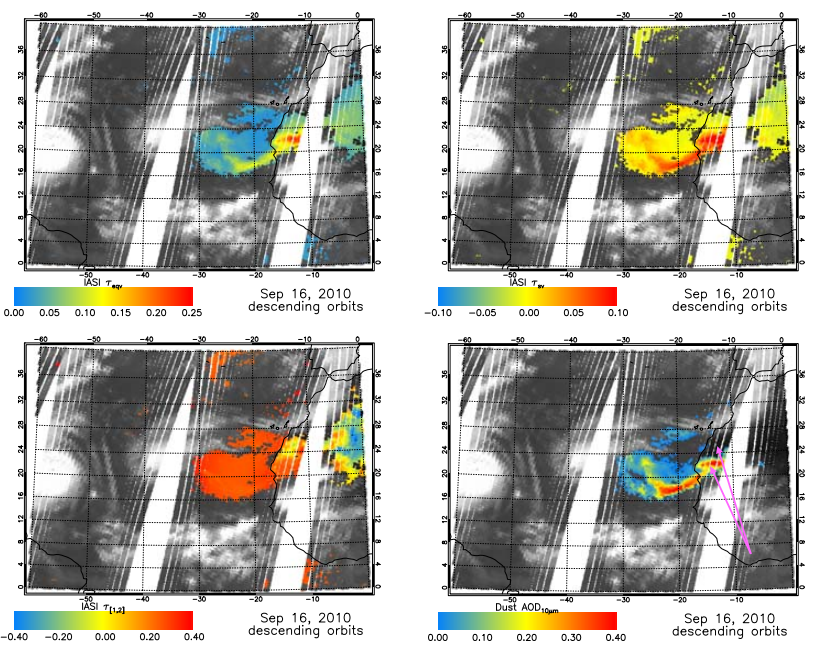

Fig. 3. Examples of internal retrieval variables and $10 \mu \mathrm{m}$ AOD for 16 September (descending orbits). These are $\tau_{\text {eqv }}$ (top left), $\tau_{\mathrm{sv}}$ (top right), $\tau_{[1,2]}$ (bottom left) and $\mathrm{AOD}_{10 \mu \mathrm{m}}$ (bottom left). The arrows indicate the position of the observations of the example $\tau$-spectra in Fig. 2.

eralogy is used for all dust models in OPAC, while Highwood et al. (2003) report a strong dependency of spectral refractive indices on mineralogy and a minor influence of the dust particle distribution. Nevertheless OPAC provides a widely used available database which represents very well the observations of e.g., Thomas et al. (2009) and is also consistent with other TIR dust models.

Given that newer (better) dust models including nonsphericity effects, other mineralogies or bi-modal particle size distributions will become available in the future, they can easily be implemented into the retrieval method - either as additional dust types or replacing the OPAC model(s).

\subsection{Singular vector decomposition of $\tau_{\text {eqv }}$-spectra}

A number of days (11-17 March 2009) with sufficient dust activity over Northern Africa, the Arabian Peninsula and also the adjacent ocean regions $\left(0^{\circ} \mathrm{N}-50^{\circ} \mathrm{N}\right.$ and $\left.30^{\circ} \mathrm{W}-70^{\circ} \mathrm{E}\right)$ has been selected for the singular vector decomposition of the IASI spectra, which have passed the initial filtering. In 
order to be sure that such a small set of days during one season is sufficient to generally represent the range of atmospheric conditions which impact on the dust retrieval, also other periods of the year 2009 have been used for singular vector decomposition. The large spatial domain provides a lot of different conditions of all types, ranging from snow covered cold surfaces in Europe to hot surfaces and high atmospheric moisture in the tropics during March. As a result the obtained singular vectors (and consequently retrieval results) were very much the same from all temporal subsets we tested, thus the original set of singular vectors obtained from March 2009 can be used in the retrieval.

For the singular vector decomposition all IASI spectra of the analysis period which passed the initial filterings (status level 3) are stored in the observation matrix $\mathbf{X}$ and the singular vector decomposition (Eq. 3) leads to a set of $n=42$ singular vectors $\boldsymbol{v}_{i \leq n}$ (right singular vectors in Eq. (3), forming a basis of the spectral space).

This singular vector approach allows for the retrieval being done in absolutely the same way for all suitable observations lover and, ocean and clouds regardless of solar illumination. The leading five basis vectors which are used for dust retrieval are depicted in Fig. 2 (right). Not surprisingly none of them can be attributed to the dust extinction spectra alone but all include partial impacts of surface emissivity and atmospheric effects.

Figure 2 also shows example spectra of a dusty and a dust free scene over the Western Sahara for different steps of the retrieval. They are aqcuired at 16 September 2010, the positions of observation are indicated by lower arrow in Fig. 3. $\tau_{\text {eqv }}$ as obtained from Eq. (4) is depicted as black curve, while the linear combination of the appropriately weighted leading five singular vectors is denominated $\tau_{\Sigma}$ and depicted in orange color. Those five singular vectors account for $91 \%$ of spectral variability as can be obtained from the respective singular values. It is evident that the black curve is quite well represented by the orange one. Tests with higher numbers of singular vectors used showed no improvement of the retrieval results.

\subsection{AOD inversion from $\tau_{\text {eqv }}$ singular vectors}

As shown in Fig. 1, after the initial filtering steps the weights $w_{i}$ of the respective singular vectors $\boldsymbol{v}_{i}$ are calculated as the scalar products of respective singular vectors and $\tau_{\text {eqv }}$ spectra:

$w_{i}=\frac{\sum_{\lambda} v_{i}(\lambda) \tau_{\mathrm{eqv}}(\lambda)}{\sqrt{\sum_{\lambda} \tau_{\mathrm{eqv}}(\lambda)^{2}}}$

where $i$ denotes the number of the corresponding singular value.

The leading two singular vectors represent mainly surface emissivity and ozone and water vapour absorption signals. The dust signal is mainly (but unfortunately not exclusively) carried by the singular vectors three to five. From the comparison of the example spectra in Fig. 2 it is clearly evident that the linear combination of singular vectors three to five $\left(\tau_{\mathrm{sv}}\right.$, Eq. 6) carries significant information in the case of observed airborne dust while it provides hardly any spectral variability for the dust free case. In the latter case almost all of the observed spectral variability is represented by the linear combination of the leading two singular vectors $\left(\tau_{[1,2]}\right.$, Eq. 10).

Due to the very strong ozone absorption peak around $9.6 \mu \mathrm{m}$ (combined with the very low surface emissivity over deserts in this spectral range) only observations between $8 \mu \mathrm{m}$ and $9 \mu \mathrm{m}$ and between $10 \mu \mathrm{m}$ and $12 \mu \mathrm{m}$ are used for the weight calculation and AOD projection to avoid the spectral regions of strongest interference of ozone and surface.

The dependence of traditional TIR retrievals on dust layer height is mainly a result of different spectral sensitivity to atmospheric layers rather than to emission by the dust (see e.g., Pierangelo et al., 2004; DeSouza-Machado et al., 2010). It can be assumed that the spectral dependence of IASI observations on dust layer height is already part of the singular vector variation, thus no height-dependent correction factors are necessary as e.g., applied by DeSouza-Machado et al. (2010).

The singular vector (SV) three to five based representation of the dust related equivalent optical depth spectrum is

$\tau_{\mathrm{sv}}(\lambda)=\sum_{j=3}^{5} w_{j} \cdot v_{j}(\lambda)$

Figures 2 and 3 also exemplarily show the contribution of $\tau_{\mathrm{sv}}$ to the overall $\tau_{\text {eqv }}$ signal.

For each of the four OPAC dust types a projection of $\tau_{\mathrm{sv}}(\lambda)$ onto a respective $\mathrm{AOD}$ spectrum with $\mathrm{AOD}_{10 \mu \mathrm{m}}=1$ is calculated as the scalar product between the singular vector based spectrum and the corresponding OPAC spectrum:

$\mathrm{AOD}_{\text {type }}=\sum_{\lambda}\left[\operatorname{AOD}_{\mathrm{opac}, \mathrm{type}}(\lambda) \cdot \tau_{\mathrm{sv}}(\lambda)\right]$

The inverse weight $\varphi_{\text {type }}$ of each OPAC type in the overall retrieval result is obtained by

$\varphi_{\text {type }}{ }^{-1}=\operatorname{acos}\left(\frac{\operatorname{AOD}_{\text {type }}}{\sqrt{\sum_{\lambda}\left(\operatorname{AOD}_{\text {opac,type }}(\lambda)\right)^{2}} \sqrt{\sum_{\lambda}\left(\tau_{\mathrm{sv}}(\lambda)\right)^{2}}}\right)(8$

which in the classical representation of the scalar product in Euclidian space would correspond to the angle between two vectors. Thus a higher value of $\varphi_{\text {type }}$ results in a better representation of the observed aerosol by the respective dust model. The weights are normalised leading to the fraction of the respective type within the dust representation.

The leading two singular vectors also carry some dust signal along the surface emissivity, ozone and water vapour influences. Their contribution to dust extinction thus is also 
needed for a complete estimation of the dust AOD in the 8$12 \mu \mathrm{m}$ band and thus for the AOD retrieval. Moreover, $\tau_{\mathrm{sv}}$ potentially still contains some surface signal which can be reduced by a correlation correction factor with respect to the first two singular vectors (see Fig. 3).

In order to estimate the necessary correction, the OPAC dust spectrum $\left(\mathrm{AOD}_{\mathrm{opac}}\right)$ and the representation of the leading two singular vectors $\left(\tau_{[1,2]}\right.$, see Fig. 3$)$ are calculated as

$$
\begin{aligned}
\operatorname{AOD}_{\text {opac }}(\lambda) & =\sum_{\text {type }}\left[\varphi_{\text {type }} \cdot \operatorname{AOD}_{\text {opac,type }}(\lambda)\right] \\
\tau_{[1,2]}(\lambda) & =w_{1} v_{1}(\lambda)+w_{2} v_{2}(\lambda)
\end{aligned}
$$

The standardized projection of $\left\{\mathbf{v}_{\mathbf{3}}, \mathbf{v}_{\mathbf{4}}, \mathbf{v}_{\mathbf{5}}\right\}$ onto $\left\{\mathbf{v}_{\mathbf{1}}, \mathbf{v}_{\mathbf{2}}\right\}$, denoted as $P_{w}$, is calculated as the scalar product of those unweighted linear combinations of singular vectors.

The signed squared linear correlation $s_{\mathrm{var}}$ between $\mathrm{AOD}_{\text {opac }}$ and $\tau_{[1,2]}$ describes the amount of variance of $\mathrm{AOD}_{\text {opac }}$ which can be explained with $\tau_{[1,2]}$ and also attributes a sign to the correlated variability.

Thus the correction term accounting for the impact of the first two singular vectors on the AOD estimated from $\tau_{\mathrm{sv}}$ is calculated as

$c_{[1,2]}=s_{\text {var }} \cdot \sum_{\text {type }}\left(\varphi_{\text {type }} \cdot P_{w} \cdot \mathrm{AOD}_{\text {type }}\right)$

This correction term is mainly positive over oceans and negative over desert soils and is added to the resulting $10 \mu \mathrm{m}$ preliminary dust optical depth $\mathrm{AOD}_{10} \mu \mathrm{m}$ :

$$
\mathrm{AOD}_{10 \mu \mathrm{m}}=\sum_{\text {type }}\left[\varphi_{\text {type }} \cdot \mathrm{AOD}_{\text {type }}\right]+c_{[1,2]}
$$

If the reulsting $\mathrm{AOD}_{10 \mu \mathrm{m}}$ is positive the respective OPAC based dust AOD spectrum

$\mathrm{AOD}_{\lambda}=\sum_{\text {type }} \mathrm{AOD}_{10 \mu \mathrm{m}} \cdot \varphi_{\text {type }} \mathrm{AOD}_{\text {opac,type }}(\lambda)$

is calculated for all $\lambda$ (all OPAC spectra have been scaled to $\left.\mathrm{AOD}_{10 \mu \mathrm{m}}=1\right)$. $\mathrm{AOD}_{\lambda}$ is then used for estimating the equivalent emission brightness temperature of the dust (being a rough indicator for dust layer effective temperature, respective height) and for temperature correction of the AOD retrieval. First the dust layer equivalent brightness temperature is calculated by inversion of Eq. (4) with a simple dust emission extension (Takashima and Masuda, 1987; Ackerman, 1997; Zhang et al., 2006):

$$
\begin{aligned}
& L_{\uparrow}(\lambda)=e^{-\mathrm{AOD}_{\lambda} / \cos \left(\Theta_{\mathrm{v}}\right)} B_{\lambda}\left(T_{\text {surface }}\right)+ \\
& \left(1-e^{-\mathrm{AOD}_{\lambda} / \cos \left(\Theta_{\mathrm{v}}\right)}\right) \epsilon_{\text {dust }} B_{\lambda}\left(T_{\text {dust }}\right)
\end{aligned}
$$

As $T_{\text {surface }}$ remains unknown, $T_{\text {base }}$ is used instead as initial guess. In one iteration of the retrieval $T_{\text {base }}$ is recalculated with the respective retrieved value of $\mathrm{AOD}_{10} \mu \mathrm{m}$ leading to a more realistic effective surface emission temperature. Especially for high AOD this may be insufficient and the underestimation of surface temperature then will result in an underestimation of dust AOD. With dust emissivity values $\epsilon_{\text {dust }}$ as reported by Takashima and Masuda (1987) for different size distributions in the $10.5-11.5 \mu \mathrm{m}$ band, this leads to

$B_{\lambda}\left(T_{\text {dust }}\right)=\frac{1}{\epsilon_{\text {dust }}} B_{\lambda}\left(T_{\text {base }}\right) \frac{e^{-\tau_{\text {eqv }}(\lambda)}-e^{-\mathrm{AOD}_{\lambda}}}{1-e^{-\mathrm{AOD}_{\lambda}}}$

This inversion is done for seven spectral bins centered at $10.5 \mu \mathrm{m}$, with the dust layer effective emission temperature being the mean value of the obtained results. After retrieval of $T_{\text {dust }}$ the observed radiance is "corrected" for thermal emission of the dust (with Eqs. 4, 5 and 14) and a second iteration of Eqs. (4) to (15) is performed leading to the final values for $\mathrm{AOD}_{10 \mu \mathrm{m}}$ and $T_{\text {dust }}$. If $T_{\text {dust }}$ is not smaller than $T_{\text {base }}$ (indicating dust aloft the ground), the dust observation is rejected as the retrieval in this case produced unphysical results.

Figure 3 shows exemplarily the initial values of $\tau_{\text {eqv }}(10 \mu \mathrm{m})$, depicted for observations with sucessful scoring test only (giving also an impression about the robustness of the scoring test). Moreover $\tau_{\text {eqv }}(10 \mu \mathrm{m}), \tau_{\mathrm{sv}}(10 \mu \mathrm{m})$ and the resulting $\mathrm{AOD}_{10 \mu \mathrm{m}}$ are presented. It is evident that $\tau_{\text {eqv }}(10 \mu \mathrm{m})$ alone is not sufficient to separate dust from surface emissivity influences; especially over The Western Sahara. Here the strong signal of surface emissivity in $\tau_{[1,2]}(10 \mu \mathrm{m})$ and the weak contrast between dust plume and water vapour absorption over ocean are evident. The dust plume is the major signal in $\tau_{\mathrm{sv}}(10 \mu \mathrm{m})$, although the negative values over land indicate the existence of minor surface emissivity contributions to $\tau_{\mathrm{sv}}(10 \mu \mathrm{m})$. Observations with $\tau_{\text {eqv }}(10 \mu \mathrm{m})$ and $\tau_{\mathrm{sv}}(10 \mu \mathrm{m})$ are all positive, but no $\mathrm{AOD}_{10 \mu \mathrm{m}}$ indicates failure of the dust retrieval due to negative projections. Although the scoring test was successfully passed, no dust is detected here (because no airborne dust is present), once more pointing out that the scoring test is not to be regarded as a dust flag.

With the weighted OPAC dust representations also a transfer coefficient between $10 \mu \mathrm{m}$ and $0.5 \mu \mathrm{m}\left(\gamma_{\text {type }}\right)$ is calculated from OPAC AOD spectra as the ratio between AOD at $0.5 \mu \mathrm{m}$ and at $10 \mu \mathrm{m}$ weighted with the respective set of $\varphi_{\text {type }}$ for each observation. These transfer coefficients of the OPAC dust types are $\gamma_{\mathrm{MINM}}=5.33522, \gamma_{\mathrm{MIAM}}=3.90652$, $\gamma_{\text {MITR }}=3.16506$ and $\gamma_{\text {coarse }}=4.35653$. They fit well within the range observed e.g. by Thomas et al. (2009). Thus (coarse mode) dust contribution to $\mathrm{AOD}_{0.5} \mu \mathrm{m}$ can also be provided as a retrieval result

$\mathrm{AOD}_{0.5 \mu \mathrm{m}}=\left(\sum_{\text {type }}\left[\varphi_{\mathrm{type}} \cdot \gamma_{\mathrm{type}}\right]\right) \cdot \mathrm{AOD}_{10 \mu \mathrm{m}}$

The weights of the different OPAC dust types and the OPAC based dust particle size distribution $\left(n_{r}\right.$ (type) $)$ lead to the estimated size distribution

$n_{r}=\sum_{\text {type }}\left[\varphi_{\mathrm{type}} \cdot n_{r}(\right.$ type $\left.)\right]$ 

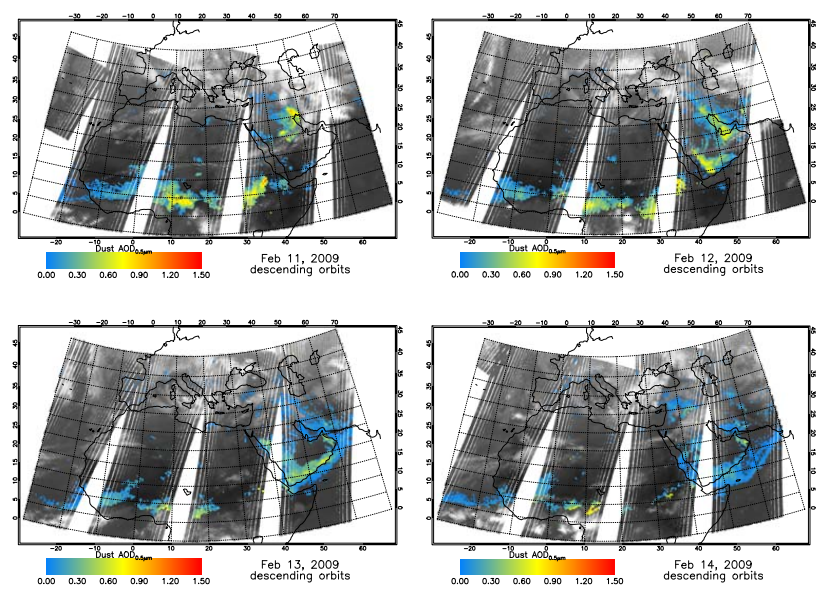

Fig. 4. IASI morning orbit observations of Dust $\mathrm{AOD}_{0.5} \mu \mathrm{m}$ (colours) and IIS temperature (greyscale) for 11-14 February 2009 (top left to bottom right).

From this size distribution the effective radius (for assumed sphericle particles) of the observed dust,

$R_{\mathrm{eff}}=\frac{\int n_{r}(r) r^{3} d r}{\int n_{r}(r) r^{2} d r}$

can directly be obtained.

An intrinsic uncertainty, which can be characterised theoretically, is composed of three parts. One part is the uncertainty which is introduced by the selection of four different fixed OPAC types and the respective weighting. This uncertainty, $\delta_{\text {type }}$, is calculated as the spread between maximum and minimum retrieved $\mathrm{AOD}_{\text {type }}$ for the four different $\mathrm{OPAC}$ models, in percent of $\mathrm{AOD}_{10 \mu \mathrm{m}}$. The second internal error source is the temperature correction. This error $\left(\delta_{\text {temp }}\right)$ is characterised by the product of the difference (absolute value) between $\mathrm{AOD}_{10 \mu \mathrm{m}}$ before and after the correction and the standard deviation of the seven different values for $T_{\text {dust }}$ obtained from seven wavelengths. Also the correction of the $10 \mu \mathrm{m}$ AOD for the contribution of the first two singular vectors is an error source $\left(\delta_{\text {corr }}\right)$. It is characterised by the fraction of the absolute value of the correction term and the sum of original prior retrieval result and correction term. The more correction is neccessary, the higher is the resulting uncertainty.

The intrinsic retrieval uncertainty then is estimated in percent as

$\delta \mathrm{AOD}_{10 \mu \mathrm{m}}=100 \% \cdot \frac{\sqrt{\left(\delta_{\text {type }^{2}}+\delta_{\text {temp }}{ }^{2}+\delta_{\text {corr }^{2}}\right)}}{\mathrm{AOD}_{10 \mu \mathrm{m}}}$

This value gives the percentage of result uncertainty due to the constraints of the retrieval mechanism (OPAC dust models and temperature correction) because of the assumptions being made. It is not to be regarded as the absolute retrieval uncertainty as obtained from validation with indepen-
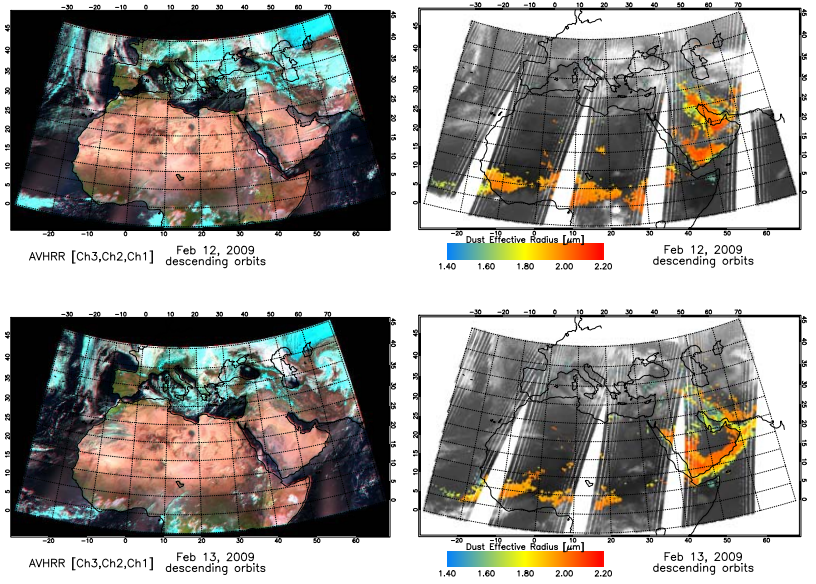

Fig. 5. AVHRR RGB composites (left) and IASI dust effective radius (right) for 12 (top) and 13 February (bottom).

dent data. Nevertheless it is an important quality measure intrinsic to the retrieval scheme which allows observations with too high internal retrieval uncertainty $\left(\delta \mathrm{AOD}_{10} \mu \mathrm{m}>50 \%\right)$ to be rejected.

\section{Dust observations and evaluation}

\subsection{Monitoring of large scale dust events}

The evolution of large scale dust events in the Sahel-Soudan belt and over Arabia is presented in Fig. 4 for four consecutive days in February 2009. Retrieved Dust $\mathrm{AOD}_{0.5 \mu \mathrm{m}}$ is plotted in colours whereas the greyscale background represents mean IIS temperature of the respective IASI observation (range from $220 \mathrm{~K}$ to $320 \mathrm{~K}$, inverted).

The observations show morning overpasses of 11-14 February 2009. On 11 February dust uplifted behind a cold front over Kuwait and Central Saudi Arabia can be observed as well as some dust activation and transport in the Sahel. The Arabian dust plume propagates further South and reaches the Yemen coast line on 12 February as well as the airborne dust covers large parts of the Persian Gulf. The dust plume has decoupled from the cold front with a Southward propagation which is faster than that of the cloud band (for decoupling of dust fronts from synoptic disturbances see e.g., Miller et al., 2008). The Sahelian dust pattern has weakened to some degree and dust transport towards the Atlantic Ocean is observed. On 13 February the dust front over Arabia has reached the Indian ocean and is re-strengthened along the Red Sea coast of Saudi Arabia. The Arabian inland dust uplift breaks down between 13 and 14 February. The Sahelian dust plume is still active over Mali and the Atlantic Ocean.

Figure 5 shows RGB composites of the Advanced Very High Resolution Radiometer (AVHRR) operated on the same spacecraft $([R, G, B]=$ channels $[1.6 \mu \mathrm{m}, 0.8 \mu \mathrm{m}, 0.6 \mu \mathrm{m}])$ and 

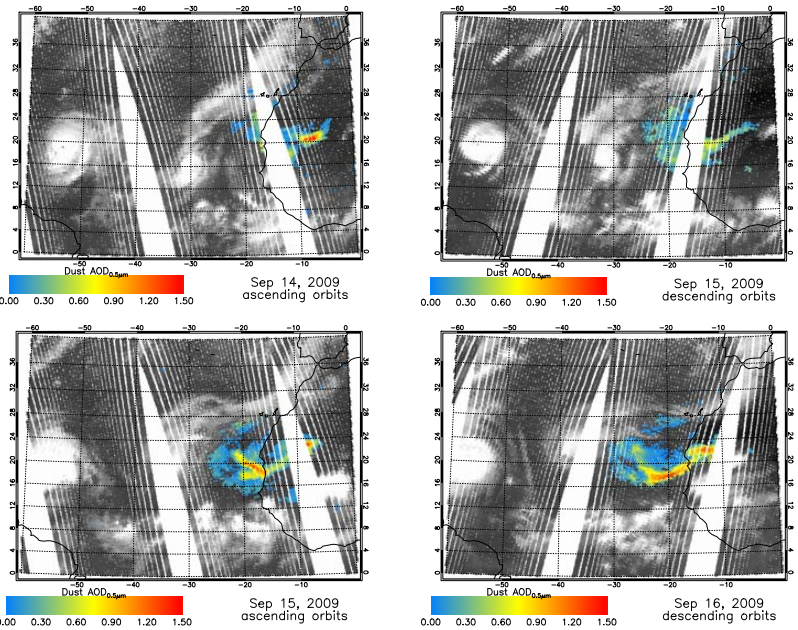

Fig. 6. IASI observations of Dust $\mathrm{AOD}_{0.5 \mu \mathrm{m}}$ (colours) and IIS temperature (greyscale) from 14 September afternoon through morning 16 September 2010.

IASI dust effective radius for 12 and 13 February daytime overpasses over Arabia and Northern Africa. On 12 February dust is visible in the AVHRR images especially over the Southern part of the Arabian Peninsula, over the Persian Gulf and in the Southern Sahel belt North of the deep convective cloud cells of the ITCZ, which very well compares to the respective AOD patterns observed with IASI. The dust plume over the Atlantic ocean has rather low AOD (Fig. 4) and thus is not really evident from the AVHRR imagery. Also the dust over the Sahara cannot be detected in the AVHRR image due to the bright underlying surface. The retrieved effective radius is rather large over the Arabian Peninsula and also slightly increased over the Persian Gulf. Over West-Africa high effective radius is observed in the Sahel near to the Sahara, while it is much lower further away from the source regions and over the Atlantic ocean (where also AOD is much lower).

On 13 February the South-Eastward propagation of the dust plume over the Indian Ocean is clearly visible from AVHRR, the pattern of higher reflectance over the ocean well fits the pattern of dust observed from IASI. Also the band of high dust AOD obtained from IASI over Western Saudi Arabia can be detected as high reflectance in the AVHRR composite image as well as the dust transport over the Southern part of the Red Sea. The dust pattern in the Sahel can be seen in the AVHRR images only very weakly, which is not very surprising as the AOD obtained from IASI are smaller than on the day before. Highest effective radii are observed in Western Arabia and over the Red Sea close to the Arabian coast, while effective radius is much lower over the Indian Ocean. Over the Sahel-Sahara source region the effective radius is slightly reduced compared to the day before and again the effective radius decreases with increasing distance to the

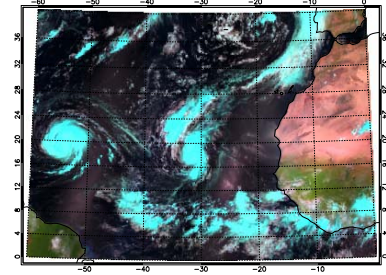

AVHRR $[$ [ H 3, Ch2, Ch 1] $] \begin{gathered}\text { sep } 15,2010 \\ \text { descending orbits }\end{gathered}$

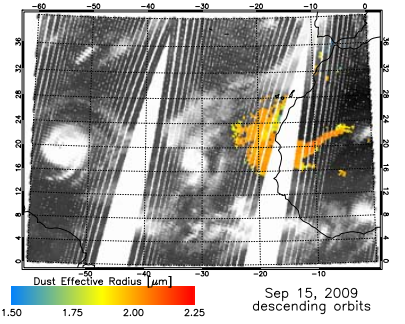

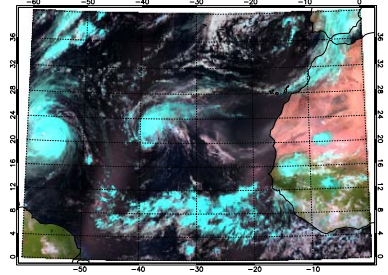

AVHRR [Ch3,Ch2,ch1] $\begin{gathered}\text { sep } 16,2010 \\ \text { descending orbits }\end{gathered}$

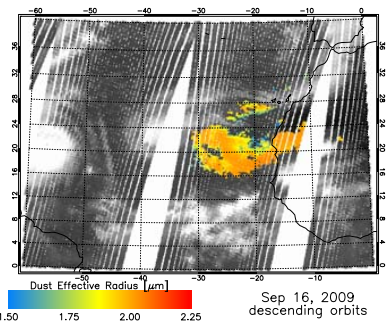

Fig. 7. AVHRR RGB composites (top) and IASI dust effective radius (bottom) for 15 (left) and 16 September (right) descending orbits.

dust source region. Lowest effective radii are observed over the Atlantic Ocean together with rather low AOD.

Figure 6 shows the evolution of a large-scale dust plume emerging from the Western Sahara towards the Atlantic Ocean from 14 through 16 September 2010 with twice daily IASI observations. The dust is emitted in the Western Sahara dust source region in the afternoon of 14 September and is first seen in IASI imagery in the ascending orbits of the same day. Near the source regions Dust AOD reaches very high values of more than 1.5 and the dust first reaches the Atlantic Ocean at the Mauretanian coast between $20^{\circ} \mathrm{N}$ and $25^{\circ} \mathrm{N}(14$ September, ascending orbits). On 15 September the plume propagates further West and also expands towards the South (the main plume now crosses the coast south of $20^{\circ} \mathrm{N}$ ). During the course of the day the dust plume also reaches the outer cloud bands of the hurricane "Julia" being active on the Eastern tropical North Atlantic Ocean. Inland dust transport towards the Atlantic Ocean still continues throughout 15 September. In the morning hours of 16 September, the dust plume over the Ocean has detached from the inland dust and travelled further West, while another dust plume is being formed near the Western Sahara source region. The Atlantic Ocean dust plume can still be seen to be in close contact with the cloud systems of hurricane "Julia".

The evolution of the dust plume can also be followed well in the AVHRR day-time composite images in Fig. 7. It is evident from the comparison of IASI AOD and AVHRR images that dust observation over (shallow cumulus) clouds is generally possible with this method. Nevertheless some potential dust above clouds is missed. For these observations the spatial homogeneity test is not passed if the cloud field is too inhomogeneous. Moreover the effective radius retrieved by IASI is depicted exemplarily for 15 September descending 
(daylight) and ascending (night time) orbits. From the effective radius retrieval it is evident that largest dust particle sizes are detected inland very close to the source region, while over the Atlantic Ocean particle sizes get much smaller.

\subsection{Evaluation against AERONET and sensitivity analysis}

Coarse mode AOD observations from the AErosol RObotic NETwork (AERONET, Holben et al., 1998) processed with the Spectral Deconvolution Algoritm (SDA, O'Neill et al., 2003) have been used for comparison with IASI derived dust AOD. One should be aware that in the SDA algorithm coarse mode AOD is somewhat sensitive to the presence of thin clouds and thus may be overestimated (O'Neill et al., 2003). All available AERONET observations over Northern hemispheric Africa, Southern Europe and the Arabian Peninsula (SDA available in 2009 for 23 stations, 577 coincidences over four months representing different seasons) are used for overpasses within a spatial distance of the observations of $50 \mathrm{~km}$ (to the center of the $12 \mathrm{~km}$ IASI FOV point-spread-function). All respective AERONET observations within half an hour deviation of the overpass are averaged and their temporal standard deviation is calculated.

Figure 8 (left) presents the resulting scatter plot between IASI derived Dust $\mathrm{AOD}_{0.5 \mu \mathrm{m}}$ and corresponding coarse mode AOD observed from AERONET. Colour coding of the symbols represents the Ångström exponent $\alpha$ of the AERONET observations (total AOD, not only coarse mode), defined by

$\frac{\mathrm{AOD}_{0.44 \mu \mathrm{m}}}{\mathrm{AOD}_{0.87 \mu \mathrm{m}}}=\left(\frac{0.44 \mu \mathrm{m}}{0.87 \mu \mathrm{m}}\right)^{\alpha}$

$\alpha$ is used quite often as indicator of aerosol particle size for mono-modal size distributions and for dust separation (e.g., Dubovik et al., 2002; Klüser and Schepanski, 2009); small $\alpha$ indicates large particle sizes. It is obvious that for most observations with co-located IASI dust observations $\alpha$ is rather small, thus in the majority of observations the aerosol is represented mainly by the coarse mode. Nevertheless there are also some observations with rather high $\alpha$, for which both IASI and AERONET coarse mode AOD are rather low.

The linear correlation between AERONET observations and IASI retrieved dust AOD is $\rho=0.623$. There is a negative bias of -0.18 , which could be expected as TIR observations are mainly sensitive to coarse mode particles (Pierangelo et al., 2005) and dust particle number size distributions normally are bi-modal in contrast to the monomodal assumption used here (Chen et al., 2010). $64 \%$ of all IASI derived AOD values are within a band of coarse mode $\mathrm{AOD}_{\mathrm{AERONET}} \pm 0.2$. The Root Mean Square Deviation (RMSD) is 0.32. Although overall performance is quite reasonable compared with AERONET (given the differences in wavelengths and observation methods as well as a potential thin cloud contamination of AERONET coarse mode AOD in

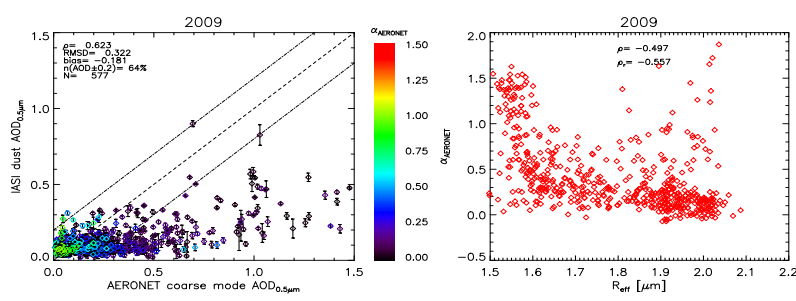

Fig. 8. Left: Evaluation of IASI Dust $\mathrm{AOD}_{0.5 \mu \mathrm{m}}$ against AERONET coarse mode $\mathrm{AOD}_{0.5} \mu \mathrm{m}$. Symbol colours represent AERONET Ångström exponent $\alpha$. Right: AERONET Ångström exponent plotted over IASI retrieved dust effective radius.

some cases and the general constribution of sea salt to coarse mode AOD observed by AERONET), it is obvious that for very high AOD the IASI retrieval underestimates AOD at $0.5 \mu \mathrm{m}$, which largely explains the rather high RMSD. These underestimations are mainly from the stations Kuwait University (in May, no data available in February), Dhadnah and Eilat.

The comparison between IASI $R_{\text {eff }}$ and $\alpha_{\text {AERONET }}$ (Fig. 8 , right) indicates that high effective radii observed by IASI correspond to rather small Ångström exponents observed by AERONET. For smaller $R_{\text {eff }}$ AERONET Ångström exponents are generally higher, indicating smaller particle sizes. The linear correlation between both is $\rho=-0.50$, but as the comparison clearly indicates (and could be expected from theory), the relationship between $R_{\mathrm{eff}}$ and $\alpha$ is not linear. The (non-linear, non-Gaussian) rank correlation coefficient (Spearman, 1908) is $\rho_{\mathrm{rank}}=-0.56$, thus has slightly higher magnitude.

Figure 9 shows time series of AERONET (coarse mode) and IASI AOD at the stations of Capo Verde (Cape-Verde Islands), Solar Village (Saudi Arabia), Tamanrassset (Algeria) and Dhadnah (United Arabian Emirates) for the months February, May and August 2009. Although also November 2009 has been processed and used here, none of the four presented stations had coincidences of AERONET and IASI dust observations in this month due to the generally very low dust activity in fall and early winter, thus the respective November time series is not shown. It is evident that in most cases the transition of dust events is well represented by the IASI observations while in Solar Village and partly in Dhadnah AOD is generally underestimated by IASI in cases with high AOD observed by AERONET. In Tamanrasset two events with high AOD in May are partly missed in the IASI observations, which is in part the result of overlying cirrus clouds at the time of the IASI observations (not shown). In Dhadnah and Tamanrasset cases with rather low AERONET coarse mode AOD and (slight) overestimation by IASI are also present. From the analysis it is clearly evident that in cases where elevated coarse mode AOD (assumed to represent mineral dust at the selected stations) is observed 

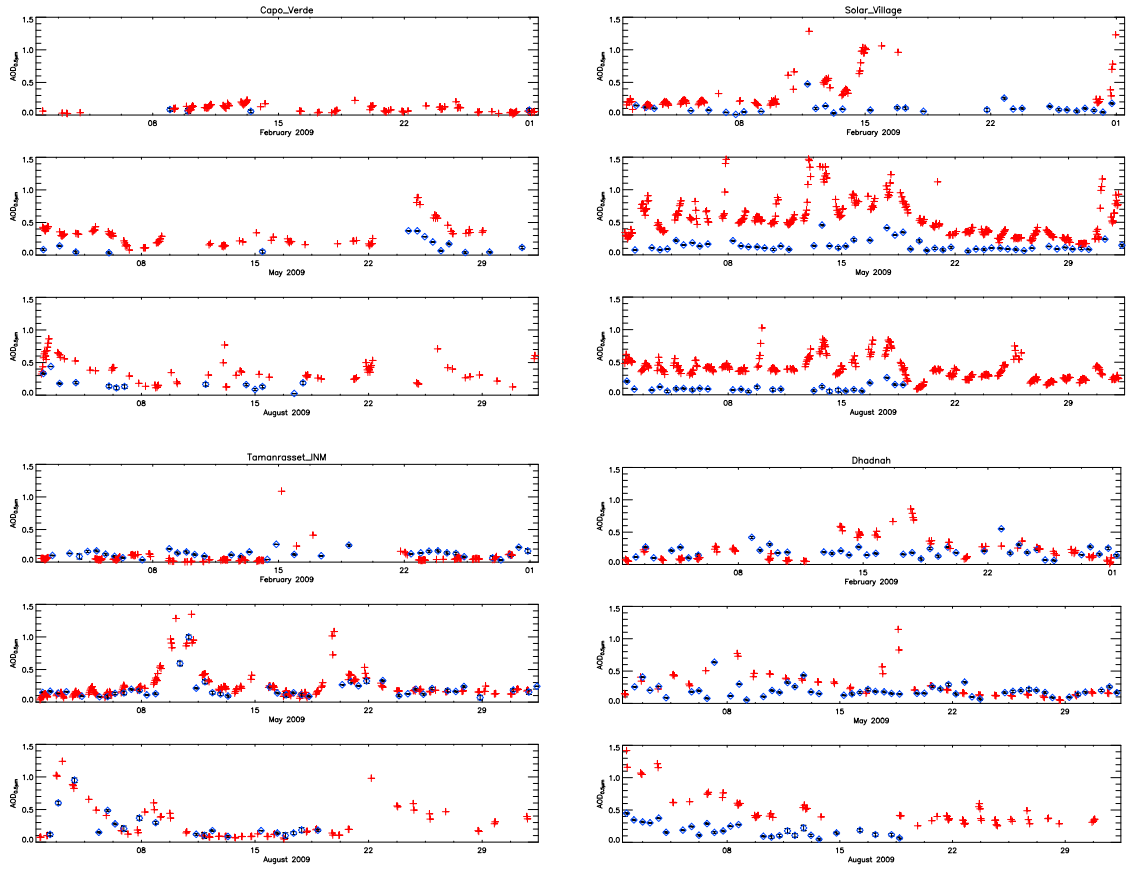

Fig. 9. Time series of AERONET coarse mode (red) and IASI (blue) derived AOD at the AERONET stations Capo Verde (top left), Solar Village (top right), Tamarasset (bottom left) and Dhadnah (bottom right) for the months February, May and August 2009.
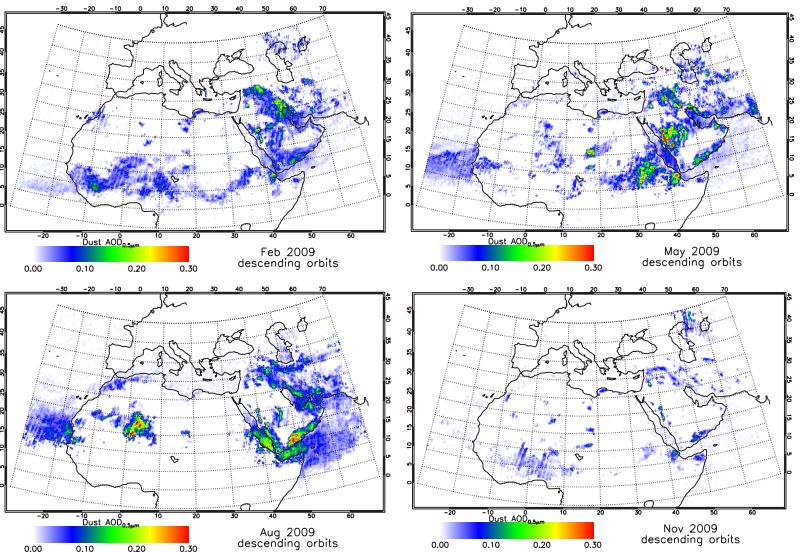

Fig. 10. IASI Dust $\mathrm{AOD}_{0.5} \mu \mathrm{m}$ for February (top left), May (top right), August (bottom left) and November (bottom right) 2009.

by AERONET the IASI retrieval also detects mineral dust. Only in Capo Verde, an island location, there are much more coarse mode observations from AERONET than from IASI, which might be the result of airborne sea salt aerosol (also being coarse mode aerosol). Time series of the other stations show very similar results but are not shown here.

For a sensitivity analysis the deviation of the IASI dust retrieval from AERONET observations

$\delta \mathrm{AOD}_{(\mathrm{IASI}, \mathrm{AERONET})}=\mathrm{AOD}_{\text {IASI }}-\mathrm{AOD}_{\mathrm{AERONET}}$ is used. Its correlation to the variable to be tested is calculated with both the linear and rank correlation. The results are given in Table 3 , where $\Delta d$ denotes the spatial distance of the FOV center to the AERONET station in $\mathrm{km}$ while $\Delta t$ is the temporal deviation (in seconds) between the IASI observation and the median (with respect to time) of the AERONET observations. The weak anti-correlation between $\delta \mathrm{AOD}_{\text {(IASI,AERONET) }}$ and IASI AOD (with magnitude of about 0.13) points towards the underestimation of high AOD by the IASI retrieval. Retrieved effective radius and temporal and spatial deviations have hardly any influence on the retrieval error as is indicated by correlations very close to zero. The same is observed for the IIS temperature variance (as long as the IIS variance threshold is applied), the retrieved dust layer emission temperature and the viewing zenith angle. The weak correlations between relative error and $T_{\text {dust }}$ can be regarded as being indicative that the dust layer height does not systematically affect the AOD retrieval (see e.g., the discussion in DeSouza-Machado et al., 2010 for height correction methodology in other TIR sounder retrievals).

\subsection{Sampling the seasonal cycle of airborne dust}

Monthly means of IASI daytime dust AOD are presented in Fig. 10 for February, May, August and November 2009, exemplarily. In February especially the high dust loads over Iraq, Kuwait and the Persian Gulf as well as over large parts of the Arabian Peninsula and the neighbouring Indian Ocean 
Table 3. Linear and rank correlations between IASI error (with respect to AERONET) and several influencing parameters.

\begin{tabular}{lccccccc}
\hline & AOD & $\Delta d$ & $\Delta t$ & $\sigma^{2}$ (IIS) & $R_{\text {eff }}$ & $T_{\text {dust }}$ & $\Theta_{\mathrm{v}}$ \\
\hline$\rho_{\text {linear }}$ & -0.128 & -0.029 & +0.024 & -0.188 & +0.062 & -0.030 & -0.034 \\
$\rho_{\text {rank }}$ & -0.128 & -0.039 & +0.007 & -0.226 & +0.065 & -0.048 & -0.021 \\
\hline
\end{tabular}

are evident. They are related to the high dust emissions connected with the Northerly Shamal wind (Laity, 2008) of the winter season. The Shamal is also responsible for dust transport towards the Indian Ocean and across the Red Sea, which is is evident from rather high AOD over these regions. Sahelian dust and transport towards the Atlantic Ocean ist the second main pattern evident from IASI AOD observations in February 2009. These are connected to the North-Easterly Harmattan wind (Laity, 2008; Pye and Tsoar, 2009; Klüser and Holzer-Popp, 2010) which activates dust throughout the Sahel belt. One clearly evident dust hot spot is the Bodélé Depression in Northern Chad, often referred to as "the most dusty place in the world" (Koren et al., 2006), and neighbouring downstream regions.

In May 2009 high dust activity can still be observed in the Bodélé Depression, but much less airborne dust is found in downstream Sahel, compared to February. Being the transition period between winter (dry season) and summer (monsoon season), also the respective dust sources have transition activity, thus the weakening of the Sahelian dust activity while in the Western Sahara the dust source regions already start being active. The Atlantic Ocean dust plume becomes stronger and is found further North than in February, while dust activity over the Arabian Peninsula and the Red Sea weakens and is more confined to some hot spot areas.

August monthly mean dust AOD is also high over the Persian gulf, the Red Sea, parts of the Arabian Peninsula and the adjacent Indian Ocean. The dust uplift and transport in this part of the world in summer is connected to the Persian Gulf trough and the tightly connected Etesian winds, which promote a cyclonic circulation around the Persian Gulf and a Westerly transport onto the Indian Ocean (Pye and Tsoar, 2009). The second well known dust hot spot in August is the large Western Saharan dust source region (e.g., Engelstaedter et al., 2006; Klüser and Schepanski, 2009; Knippertz and Todd, 2010) and the strong advection towards the Atlantic Ocean.

In November, after the retreat of the West-African Monsoon (e.g., Klüser and Holzer-Popp, 2010), dust activity is very low throughout the whole observation area, some larger scale dust activity can be observed in the Sahel and North of the Persian Gulf.

\section{Discussion}

The retrieval method for IASI presented here is based on Singular Vector Decomposition of equivalent optical depth spectra rather than on radiative transfer modelling and lookup tables (LUTs). The high variability of spectral surface emissivity of desert soils together with the evident lack of knowledge about its spatial distributions (no reliable spectral emissivity maps available) complicate every radiative transfer modelling based approach of dust remote sensing in the TIR over deserts. Either one tries to retrieve emissivity and dust properties simultaneously (computationally very expensive and not always possible), or one has to use other approaches than radiative transfer modelling, if reliable results are desired also for arid land regions. One such approach is the singular vector decomposition and the accompanying projection scheme used here.

As it does not rely on an external cloud mask but only on internal cloud filtering, the SVD based retrieval is also capable of retrieving dust information above low clouds beneath the dust layer.

Another advantage of thermal infrared observations in the $8-12 \mu \mathrm{m}$ is the independence from sunlight, so that dust observation is possible twice daily with the SVD based approach from IASI. All three events presented here strongly indicate that there is high consistancy of morning and afternoon observations which allows to twice daily sample the evolution of airborne dust.

Dust AOD retrieved from IASI correlates quite well with AERONET coarse mode AOD given the asumptions and constraints of the retrieval and the fact that IASI is only sensitive to the coarse mode dust particles being responsible for considerable extinction in the $8-12 \mu \mathrm{m}$ band.

The time series analysis of the four AERONET stations show exemplarily that the transition of dust events is well captured by IASI observations throughout all seasons. Although IASI observations tend to underestimate $\mathrm{AOD}_{0.5} \mu \mathrm{m}$ in scenes with high AOD, potentially due to the intrinsic underestimation of surface temperature in these cases, the ability of IASI dust detection in cases of elevated coarse mode $\mathrm{AOD}_{0.5 \mu \mathrm{m}}$ is clearly evident. The $\mathrm{AOD}_{0.5} \mu \mathrm{m}$ underestimation is higher in the Solar Village time series than e.g., in Tamarasset or Cabo Verde. The highest underestimation is found for Kuwait University in May. 
The stations with most significant $\mathrm{AOD}_{0.5} \mu \mathrm{m}$ underestimations (Kuwait University, Dhadnah, Eilat) are close to the sea, the Kuwait University station moreover is located directly inside Kuwait City. Thus coarse mode AOD contributions of other aerosols than dust, especially from near-surface particulate matter or sea-salt, cannot be excluded. Moreover all three stations are in environments of very inhomogeneous surface types (urban, desert, ocean), which might also impact on the strength of the dust signal in the IASI observations. Thus for these stations it is not very surprising that within a $50 \mathrm{~km}$ circle partly large deviations from AERONET observations occur.

Also AERONET coarse mode AOD retrieved with the SDA algorithm has some limitations and weaknesses. O'Neill et al. (2003) state that for coarse mode aerosol there is some sensitivity to thin homogeneous cloud contamination. While they report that given this sensitivity the fine mode AOD is not much affected by this problem, this is not true for the coarse mode AOD which has been used here. Although it is quite unlikely that cirrus is present in IASI observations due to the strong thermal signal of these clouds, they may well be present in AERONET observations within the $50 \mathrm{~km}$ distance and $0.5 \mathrm{~h}$ deviation from the IASI observations.

One a-priori assumption of the retrieval mechanism is the validity of OPAC extinction spectra. There is evidence that AOD spectra observed in the Sahara compares quite well with OPAC in the TIR, but as OPAC assumed log-normal size distributions it is not clear if the transfer to $\mathrm{AOD}_{0.5 \mu \mathrm{m}}$ can be done more precisely with a better dust aerosol representation. The same might be the case for including non-sphericity effects in the dust model. As so far no suitable dust representation including bi-modal size distributions and non-sphericity is available for remote sensing applications in the thermal infrared, the choice of four different OPAC models remains the preferred dust representation. The comparison to AERONET and the possibility to follow the evolution of the dust plumes in the IASI observations shows that the OPAC assumption, while not being perfect, performs reasonably well. Future work will focus on evaluation of the effective radius estimation from the OPAC size distribution assumptions.

In some cases rather high Ångström exponent $\alpha$ is observed, indicating that the majority of the total aerosol burden of these observations is not of the coarse mode. For these observations both, IASI AOD and AERONET coarse mode AOD are rather small. Thus there is evidence that it is really only the dust fraction of the total aerosol burden, which is observed by IASI with the presented method. This conclusion is supported by the results of a comparison of IASI AOD with AERONET total AOD (not shown). For total AOD the evaluation results get much worse with a linear correlation coefficient $\rho=0.524$, RMSD $=0.479$ and bias $=-0.367$. Thus compared to total AERONET AOD there is a very strong underestimation of AOD by IASI, which can easily be attributed to the fine mode fraction of the aerosol.
MODIS "Deep Blue" validation against AERONET shows that "Deep Blue" AOD values are generally within $20 \%$ to $30 \%$ of AERONET observations, also over deserts. No correlation coefficients or RMSD values are reported for the "Deep Blue" validation (Hsu et al., 2004, 2006). MISR AOD reaches correlation coefficients larger than 0.7 over desert regions and larger than 0.9 over oceans. Both products are total AOD retrievals based on reflected solar radiation. Thus, although performing somewhat weaker in the AERONET comparison (correlation of about 0.62 ), the IASI method presented here still performs reasonably well taking into account that only Dust AOD is observed (which moreover is transferred from TIR to $0.5 \mu \mathrm{m}$ ) and that it is a thermal infrared retrieval.

Although no quantitative validation of the effective radius has been performed, the comparison of $R_{\text {eff }}$ with AERONET Ångström exponent indicates that the effective radius based on OPAC dust type size distributions provides at least some qualitative information about the size distribution of airborne dust particles. Generally the spatial distributions of effective radius with larger $R_{\text {eff }}$ near source regions and lower $R_{\text {eff }}$ over the oceans seem to look quite reasonable.

For $T_{\text {dust }}$, no evaluation has been performed so far, thus also no $T_{\text {dust }}$ results are shown here. Future work will focus on the potential of retrieving dust layer height information from $T_{\text {dust }}$ quantitatively.

The error correlation analysis with AERONET data shows that the underestimation of high AOD and small effective radii representing conditions with rather small dust particles being airborne are the largest error sources. Small effective radii are connected with a rather wide range of AERONET Ångström exponents, which indicates that in those cases the particle size distribution assumption (or the mineralogy) of OPAC seems to be invalid. This invalidity might be the result of bi-modal particle size distributions instead of the mono-modal lognormal distributions assumed in the OPAC database, as discussed above. For larger effective radii there seems to be a quite reasonable relationship between Ångström exponent from AERONET and estimated effective radius.

Both observations during day and night conditions have been presented here showing the potential of TIR sounder observations for dust retrieval regardless of solar illumination. Nevertheless due to the lack of corresponding independent nighttime data almost all validation steps are performed during daytime. Evidence for the nighttime retrievals being as good as the daytime retrieval is given (only) by the general agreement of day- and nighttime observations of the specific events (plausible evolutions of the dust plumes).

The monthly means of dust AOD presented for February, May, August and November 2009 represent well the seasonal cycle of mineral dust as e.g., described in N'Tchayi Mbourou et al. (1997); Engelstaedter et al. (2006); Laity (2008); Klüser and Holzer-Popp (2010); and Knippertz and Todd (2010). Especially in the Sahelian dry season (mainly February) the 
IASI dust AOD reveals the possibility of separating dust from undetected biomass burning AOD, which has very strong influence especially on the aerosol plume over the Atlantic Ocean (rather weak in the IASI observations).

The SVD approach for dust retrieval from TIR observations with IASI combines a number of major strengths and advantages. These can be summarized as:

- The retrieval is sensitive to mineral dust only, allowing for a clear distinction from other aerosol types.

- The retrieval works at day and night and thus provides observations twice daily from a polar orbiting spacecraft.

- No a priori assumption about the atmospheric state is necessary.

- The influence of surface emissivity on the dust retrieval can be reduced and no emissivity database is necessary.

- Four OPAC dust types allow for variable size distributions of dust particles.

- Dust can be retrieved over clouds.

- It is very easy to add new dust models to the retrieval without the necessity of radiative transfer calculations.

- Effective radius and dust emission temperature are retrieved simultaneously together with AOD.

As is always the case, those strengths are also closely related to some limitations and disadvantages of the retrieval method:

- AOD is retrieved at $10 \mu \mathrm{m}$ and then transfered to $0.5 \mu \mathrm{m}$. The transfer coefficients are based on OPAC.

- The OPAC dust models do not allow for different mineralogy, which mainly determines the shape of the extinction spectrum in the TIR.

- Non-sphericity effects of dust extinction are not accounted for.

- Surface temperature is underestimated at high TIR AOD, hence an underestimation of AOD itself. More retrieval iterations do not provide substantial improvements.

- Effective radius is not independently retrieved but only the weighted combination of the respective OPAC size distributions.

\section{Conclusions and outlook}

A new approach of retrieving desert dust optical depth from IASI observations has been presented. The retrieval is based on a singular vector decomposition of IASI spectra in the $8-12 \mu \mathrm{m}$ band rather than on direct simulation of radiative transfer. Avoiding radiative transfer modelling and making use of the decomposition of the IASI spectra in uncorrelated (orthogonal) principal components allows for a separation of surface emissivity and dust signals without the need for a-priori assumptions of emissivity spectra. Moreover the method does not rely on a-priori assumptions of atmospheric temperature and humidity profiles as maximum brightness temperature per bin is used instead of single-channel radiance. A set of singular vectors is determined from several days of IASI observations over the Sahara-Arabia domain.

Two different cases of dust events over Northern Africa and Arabia show good performance in dust detection with the IASI method. Being a thermal infrared method (8$12 \mu \mathrm{m}$ band), the IASI retrieval provides observations independent from solar illumination conditions and thus is capable of dust observations twice daily. Good correspondence between day and night observations is found. AOD retrieved from IASI correlates reasonably well with AERONET coarse mode AOD while the IASI retrieval tends to underestimate high AOD. Comparison with AERONET time series shows that the evolution of transient dust events is well captured by the IASI observations. The use of different OPAC dust types with different size distributions offers the possibility to retrieve not only dust AOD but also to estimate effective radius by means of contributions of the different OPAC types to total dust AOD. Comparison with AERONET Ångström exponent indicates that the retrieved dust particle effective radius carries at least qualitative information about the particle size distribution. During the retrieval also the dust emission temperature is estimated. Moreover also the intrinsic uncertainty of AOD is determined. Thus every single retrieved AOD is accompanied by an intrinsic uncertainty value based on dust type (which means particle size distribution), dust temperature and singular vector projection errors. The delivery of pixel-wise uncertainty estimations is a great advantage in many applications as selections of subsets of observations can be made based on the desired degree of reliability.

Dust related research such as e.g., dust-cloud interaction studies will clearly benefit from the increased sampling rate (twice daily). Especially the potential of dust observation after sunset, when deep convective systems over land are much more pronounced than in the morning hours, is a great opportunity for such studies. Moreover results largely depend on the aerosol type, while a proper discrimination of dust contribution from other aerosol types has been shown to be of great importance (Klüser and Holzer-Popp, 2010).

Another possible application is a revision of dust source area activation frequency maps used e.g., for numerical modelling of mineral dust (Tegen, 2003; Schepanski et 
al., 2007). The sampling rate of observations twice daily can also offer some help to understand the diurnal cycle of dust activity near source regions (Schepanski et al., 2007) and to revise applications based on the diurnal cycle of dust activity (Klüser and Schepanski, 2009; Klüser and Holzer-Popp, 2010).

Assimilation of aerosol optical depth into numerical modelling systems ideally would require assumptions about the type of aerosol, their size distribution and their vertical profile together with pixel-wise error estimates of these variables. The IASI retrieval can provide AOD of mineral dust clearly separated from other aerosol contributions. It moreover provides an estimate of the dust particle size distribution and, together with the temperature profile of the model system, possibly some height information. Moreover each observation is accompanied by an independent uncertainty estimation. Thus the IASI retrieval meets several of the key requirements of data assimilation and might prove very useful in this context.

The IASI dust observations will soon become available in the World Data Center for Remote Sensing of the ATmosphere (WDC-RSAT), mandated by ICSU and WMO and hosted by the German Remotesensing Datacenter (http://wdc.dlr.de).

Acknowledgements. We thank two anonymous reviewers for their very constructive comments which helped to improve this manuscript. We thank all AERONET station Principal Investigators and their staff for establishing and maintaining the 23 AERONET sites used for evaluation and for providing the observation data. We are thankful to EUMETSAT and the EUMETSAT Data Centre (UMARF) for providing the IASI and AVHRR observations from METOP.

Edited by: A. Lambert

\section{References}

Ackerman, S. A.: Remote sensing aerosol using satellite infrared observations, J. Geophys. Res., 102(D14), 17069-17079, 1997.

Ansmann, A., Tesche, M., Althausen, D., Müller, D., Seifert, P., Freudenthaler, V., Heese, B., Wiegner, M., Pisani, G., Knippertz, P., and Dubovik, O.: Influence of Saharan dust on cloud glaciation in Southern Morocco during the Saharan Mineral Dust Experiment, J. Geophys. Res., 113, D04210, doi:10.1029/2007JD008785, 2008.

Aumann, H. H., Chahine, M. T., Gautier, C., Goldberg, M. D., Kalnay, E., McMillin, L. M., Revercomb, H., Rosenkranz, P. W., Smith, W. L., Staelin, D. H., Strow, L. L., and Susskind, J.: AIRS/AMSU/HSB on the Aqua mission: design, science objectives, data products, and processing systems, IEEE Trans. Geosci. Remote Sens., 41, 253264, 2003.

Blumstein, D., Chalon, G., Carlier, T., Buil, C., Hebert, P., Maciaszek, T., Ponce, G., Phulpin, T., Tournier, B., Simeoni, D., Astruc, P., Clauss, A., Kayal, G., and Jegou, R.: IASI instrument: Technical overview and measured performances, in: Society of
Photo-Optical Instrumentation Engineers (SPIE) Conference Series, edited by: Strojnik, M., Vol. 5543, 2004.

Breitkreuz, H., Schroedter-Homscheidt, M., and Holzer-Popp, T.: A case study to prepare for the utilization of aerosol forecasts in solar energy industries, Sol. Energy, 81, 1377-1385, 2007.

Brindley, H. E. and Ignatov, A.: Retrieval of mineral aerosol optical depth and size information from Meteosat Second Generation SEVIRI solar reflectance bands, Remote Sens. Environ., 102, 344-363, 2006.

Chaboureau, J.-P., Tulet, P., and Mari, C.: Diurnal cycle of dust and cirrus over West Africa as seen from Meteosat Second Generation satellite and a regional forecast model, Geophys. Res. Lett., 34, L02882, doi:10.1029/2006GL027771, 2007.

Chen, G., Ziemba, L. D., Chu, D. A., Thornhill, K. L., Schuster, G. L., Winstead, E. L., Diskin, G. S., Ferrare, R. A., Burton, S. P., Ismail, S., Kooi, S. A., Omar, A. H., Slusher, D. L., Kleb, M. M., Reid, J. S., Twohy, C. H., Zhang, H., and Anderson, B. E.: Observations of Saharan dust microphysical and optical properties from the Eastern Atlantic during NAMMA airborne field campaign, Atmos. Chem. Phys. Discuss., 10, 13445-13493, doi:10.5194/acpd-10-13445-2010, 2010.

Chylek, P., Robinson, S., Dubey, M. K., King, M. D., Fu, Q., and Clodius, W. B.: Comparison of near-infrared and thermal infrared cloud phase detections, J. Geophys. Res., 111, D20203, doi:10.1029/2006JD007140, 2006.

DeSouza-Machado, S. G., Strow, L. L., Imbiriba, B., McCann, K., Hoff, R. M., Hannon, S. E., Martins, J. V., Tanré, D., Deuzé, J. L., Ducos, F., and Torres, O.: Infrared retrievals of dust using AIRS: Comparisons of optical depths and heights derived for a North African dust storm to other collocated EOS ATrain and surface observations, J. Geophys. Res., 115, D15201, doi:10.1029/2009JD012842, 2010.

Diner, D. J., Martonchik, J. V., Kahn, R. A., Pinty, B., Gobron, N., Nelson, D. L., and Holben, B. N.: Using angular and spectral shape similarity constraints to improve MISR aerosol and surface retrievals over land, Remote Sens. Environ., 94, 155-171, 2005.

Dubovik, O., Holben, B., Eck, T. F., Smirnov, A., Kaufman, Y. J., King, M. D., Tanré, D., and Slutsker, I.: Variability of absorption and optical properties of key aerosol types observed in worldwide locations, J. Atmos. Sci., 59, 590-608, 2002.

Dufresne, J.-L., Gautier, C., Ricchiazzi, P., and Fouquart, Y.: Longwave scattering effects of mineral aerosols, J. Atmos. Sci., 59, 1959-1966, 2002.

Dunion, J. P. and Velden, C. S.: The impact of the Saharan Air Layer on Atlantic tropical cyclone activity, B. Am. Meteorol. Soc., 85, 353-365, 2004.

Engelstaedter, S., Tegen, I., and Washington, R.: North African dust emissions and transport, Earth-Sci. Rev., 79, 73-100, 2006.

Evan, A. T., Dunion, J., Foley, J. A., Heidinger, A. K., and Velden, C. S.: New evidence for a relationship between Atlantic tropical cyclone activity and African dust outbreaks, Geophys. Res. Lett., 33, L19813, doi:10.1029/2006GL026408, 2006a.

Evan, A. T., Heidinger, A. K., and Pavolonis, M. J.: Development of a new over-water advanced very high resolution radiometer dust detection algorithm, Int. J. Remote Sens., 27, 3903-3924, 2006 b.

Fouquart, Y., Bonnel, B., Brogniez, G., Buriez, J., Smith, L., and Morcrette, J.-J.: Observations of Saharan aerosols: results of ECLATS field experiment: Part II. Broadband radiative characteristics of aerosols and vertical flux divergence, J. Clim. Appl. 
Meteorol., 26, 38-52, 1987.

Jickells, T. D., An, Z. S., Andersen, K. K., Baker, A. R., Bergametti, G., Brooks, N., Cao, J. J., Boyd, P. W., Duce, R. A., Hunter, K. A., Kawahata, H., Kubilay, N., la Roche, J., Liss, P. S., Mahowald, N., Prospero, J. M., Ridgwell, A. J., Tegen, I., and Torres, R.: Global iron connections between desert dust, ocean biogeochemistry, and climate, Science, 308, 67-71, 2005.

Hess, M., Köpke, P., and Schult, I.: Optical properties of aerosols and clouds: the software package OPAC, B. Am. Meteorol. Soc., 79, 831-844, 1998.

Highwood, E., Haywood, J., Silverstone, M., Newman, S., and Taylor, J.: Radiative properties and direct effect of Saharan dust measured by the C-130 aircraft during Saharan Dust Experiment (SHADE): 2. Terrestrial spectrum, J. Geophys. Res., 108(D18), 8578, doi:10.1029/2002JD002552, 2003.

Holben, B. N., Eck, T. F., Slutsker, I., Tanre, D., Buis, J. P., Setzer, A., Vermote, E., Reagan, J. A., Kaufman, Y. J., Nakajima, T., Lavenu, F., Jankowiak, I., and Smirnov, A.: AERONET - a federated instrument network and data archive for aerosol characterization, Remote Sens. Environ., 66, 1-16, 1998.

Holzer-Popp, T., Schroedter-Homscheidt, M., Breitkreuz, H., Martynenko, D., and Klüser, L.: Improvements of synergetic aerosol retrieval for ENVISAT, Atmos. Chem. Phys., 8, 7651-7672, doi:10.5194/acp-8-7651-2008, 2008.

Hui, W. J., Cook, B. I., Ravi, S., Fuentes, J. D., and D'Odorico, P.: Dust-rainfall feedbacks in the West African Sahel, Water Resour. Res., 44, W05202, doi:10.1029/2008WR006885, 2008.

Hulley, G. C., Hook, S. J., Manning, E., Lee, S.-Y., and Fetzer, E.: Validation of the Atmospheric Infrared Sounder (AIRS) version 5 land surface emissivity product over the Namib and Kalahari deserts, J. Geophys. Res., 114, D19104, doi:10.1029/2009JD012351, 2009.

Hsu, N. C., Tsay, S. C., King, M. D., and Herman, J. R.: Aerosol properties over bright-reflecting source regions, IEEE T. Geosci. Remote, 42, 557-569, 2004.

Hsu, N. C., Tsay, S. C., King, M. D., and Herman, J. R.: Deep blue retrievals of Asian aerosol properties during ACE-Asia, IEEE T. Geosci. Remote, 44, 3180-3195, 2006.

Jenkins, G. S., Pratt, A. S., and Heymsfield, A.: Possible linkage between Saharan dust and tropical cyclone rain band invigoration in the Eastern Atlantic during NAMMA-06, Geophys. Res. Lett., 25, L08815, doi:10.1029/2008GL034072, 2008.

Kahn, R., Gaitley, B., Martonchik, J., Diner, D., Crean, K., and Holben, B.: Multiangle Imaging Spectroradiometer (MISR) global aerosol optical depth validation based on 2 years of coincident Aerosol Robotic Network (AERONET) observations, J. Geophys. Res., 110, D10S04, doi:10.1029/2004JD004706, 2005.

Kalashnikova, O. V. and Sokolik, I. N.: Modeling the radiative properties of nonspherical soil-derived mineral aerosols, J. Quant. Spectrosc. Ra., 87, 137-166, 2004.

Kalashnikova, O. V., Kahn, R., Sokolik, I. N., Li, W. H.: Ability of multiangle remote sensing observations to identify and distinguish mineral dust types: Optical models and retrievals of optically thick plumes, J. Geophys. Res., 110(D18), D18S14, doi:10.1029/2004JD004550, 2005.

King, M. D., Kaufman, Y. J., Tanré, D., and Nakajima, T.: Remote sensing of tropospheric aerosols from space: past, present and future, B. Am. Meteorol. Soc., 80, 2229-2259, 1999.

Klüser, L. and Holzer-Popp, T.: Relationships between mineral dust and cloud properties in the West African Sahel, Atmos. Chem. Phys., 10, 6901-6915, doi:10.5194/acp-10-6901-2010, 2010.

Klüser, L. and Schepanski, K.: Remote sensing of mineral dust over land with MSG infrared channels: a new Bitemporal Mineral Dust Index, Remote Sens. Environ., 113, 1853-1867, 2009.

Knippertz, P. and Todd, M. C.: The Central West Saharan dust hot spot and its relation to African easterly waves and extratropical disturbances, J. Geophys. Res., 115, D12117, doi:10.1029/2009JD012819, 2010.

Kokhanovski, A. A. and de Leeuw, G. (Eds.): Satellite aerosol remote sensing over land, Springer, Heidelberg, Berlin, Germany, 2009.

Koren, I., Kaufman, Y. J., Washington, R., Todd, M. C., Rudich, Y., Martins, J. V., and Rosenfeld, D.: The Bodélé depression: a single spot in the Sahara that provides most of the mineral dust to the Amazon forest, Environ. Res. Lett., 1, 014005, 5 pp., doi:10.1088/1748-9326/1/1/014005, 2006.

Laity, J.: Deserts and Desert Environments, Environmental Systems and Global Change Series, John Wiley \& Sons, Chichester, UK, 2008.

Larar, A. M., Smith, W. L., Zhou, D. K., Liu, X., Revercomb, H., Taylor, J. P., Newman, S. M., and Schlüssel, P.: IASI spectral radiance validation inter-comparisons: case study assessment from the JAIVEx field campaign, Atmos. Chem. Phys., 10, 411-430, 2010 , http://www.atmos-chem-phys.net/10/411/2010/.

Legrand, M., Plana-Fattori, A., and N'doume, C.: Satellite detection of dust using the IR imagery of Meteosat, 1. Infrared difference dust index, J. Geophys. Res., 106, 18251-18274, 2001.

Li, J., Zhang, P., Schmit, T. J., Schmetz, J., and Menzel, W. P.: Quantitative monitoring of a Saharan dust event with SEVIRI on Meteosat-8, Int. J. Remote Sens., 28, 2181-2186, 2007.

Mahowald, N. M. and Kiehl, L. M.: Mineral aerosol and cloud interactions, Geophys. Res. Lett., 30, 1475, doi:10.1029/2002GL016762, 2003.

Mahowald, N. M., Baker A. R., Bergametti, G., Brooks, N., Duce, R. A., Jickells, T. D., Kubilay, N., Prospero, J. M., and Tegen, I.: Atmospheric global dust cycle and iron inputs to the ocean, Global Biogeochem. Cy., 19, GB4025, doi:10.1029/2004GB002402, 2005.

Matricardi, M.: A principal component based version of the RTTOV fast radiative transfer model, Q. J. Roy. Meteor. Soc., 136, 1823-1835, doi:10.1002/qj.680, 2010.

Meland, B., Kleiber, P. D., Grassian, V. H., and Young, M. A.: Correlated IR spectroscopy and visible light scattering measurements of mineral dust aerosol, J. Geophys. Res., 115, D20208, doi:10.1029/2010JD014389, 2010.

Miller, S. D., Kuciauskas, A. P., Liu, M., Ji., Q., Reid, J. S., Breed, D. W., Walker, A. L., and Mandoos, A. A.: Haboob dust storms of the Southern Arabian Peninsula, J. Geophys. Res., 112, D01202, doi:10.1029/2007JD008550, 2008.

N'Tchayi Mbourou, G., Bertrand, J. J., and Nicholson, S. E.: The diurnal and seasonal cycle of wind-borne dust over Africa north of the equator, J. Appl. Meteorol., 36, 868-882, 1997.

O’Neill, N. T., Eck, T. F., Smirnov, A., Holben, B. N., and Thulasiraman, S.: Spectral discrimination of coarse and fine mode optical depth, J. Geophys. Res., 108(D17), 4559-4573, doi:10.1029/2002JD002975, 2003.

Ogawa, K., Schmugge, T., and Jacob, F.: Estimation of land 
surface window $(8-12 \mu \mathrm{m})$ emissivity from multispectral thermal infrared remote sensing - A case study in a part of Sahara Desert, Geophys. Res. Lett., 30, 30(2), 1067, doi:10.1029/2002GL016354, 2003.

Peyridieu, S., Chédin, A., Tanré, D., Capelle, V., Pierangelo, C., Lamquin, N., and Armante, R.: Saharan dust infrared optical depth and altitude retrieved from AIRS: a focus over North Atlantic - comparison to MODIS and CALIPSO, Atmos. Chem. Phys., 10, 1953-1967, doi:10.5194/acp-10-1953-2010, 2010.

Pierangelo, C., Chédin, A., Heilliette, S., Jacquinet-Husson, N., and Armante, R.: Dust altitude and infrared optical depth from AIRS, Atmos. Chem. Phys., 4, 1813-1822, doi:10.5194/acp-41813-2004, 2004.

Pierangelo, C., Mishchenko, M., Balkanski, Y., and Cédin, A.: retrieving the effective radius of Saharan dust coarse mode from AIRS, Geophys. Res. Lett., 32, L20813, doi:10.1029/2005GL023425, 2005.

Pye, K. and Tsoar, H.: Aeolian Sand and Sand Dunes, Springer, Berlin, Germany, 2009.

Rodgers, C. D.: Inverse methods for atmospheric sounding, Theory and practice, in: Series on Atmospheric, Oceanic and Planetary Physics, vol. 2, World Scientific Publishing, Singapore, 2000.

Rosenfeld, D., Rudich, Y., and Lahev, R.: Desert dust suppressing precipitation: a possible desertification feedback loop, P. Natl. Acad. Sci. USA, 98, 5975-5980, 2001.

Schepanski, K., Tegen, I., Laurent, B., Heinold, B., and Macke, A.: A new Saharan dust source activation frequency map derived from MSG-SEVIRI IR-channels, Geophys. Res. Lett., 34, L18803, doi:10.1029/2007GL030168, 2007.

Seemann, S. W., Borbas, E.:, Knuteson, R. O., Stephenson, G. R., and Huang, H.-L.: Development of a Global Infrared Land Surface Emissivity DAtabase for Application to Clear Sky Sounding Retrievals from Multi-spectral Satellite Radiance Measurements, J. Appl. Meteor. Climatol., 47, 108-123, 2008.

Shenk, W. E. and Curran, R. J.: The detection of dust storms over land and water with satellite visible and infrared measurements, Mon. Weather Rev., 102, 830-837, 1974.
Slingo, A., Ackerman, T. P., Allan, R. P., Kassianov, E. I., McFarlane, S. A., Robinson, G. J., Barnard, J. C., Miller, M. A., Harries, J. E., Russell, J. E., and Dewitte, S.: Observations of the impact of a major Saharan dust storm on the atmospheric radiation balance, Geophys. Res. Lett., 33, L24817, doi:10.1029/2006GL027869, 2006.

Sokolik, I., Andronova, A., and Johnson, T. C.: Complex refractive index of atmospheric dust aerosols, Atmos. Environ. A, 27, 2495-2502, 1993.

Sokolik, I., Toon, O., and Bergstrom, R.: Modeling the radiative characteristics of airborne mineral aerosols at infrared wavelengths, J. Geophys. Res., 103, 8813-8826, 1998.

Spearman, C.: The method of "right and wrong cases" (constant stimuli) without Gauss' formulae, Brit. J. Psychol., 2, 227-242, 1908.

Takashima, T. and Masuda, K.: Emissivities of quartz and sahara dust powders in the infrared region $(7-17 \mu \mathrm{m})$, Remote Sens. Environ., 23, 51-63, 1987.

Tegen, I.: Modeling the mineral dust aerosol cycle in the climate system, Quaternary Sci. Rev., 22, 1821-1834, 2003.

Thomas, M., Gautier, C., and Ricchiazzi, P.: Investigations of the March 2006 African dust storm using ground-based columnintegrated high spectral resolution infrared $(8-13 \mu \mathrm{m})$ and visible aerosol optical thickness measurements: 1. Measurement procedures and results, J. Geophys. Res., 114, D11202, doi:10.1029/2008JD010928, 2009.

Torres, O., Bhartia, P. K., Herman, J. R., Ahmad, Z., and Gleason, J.: Derivation of aerosol properties from a satellite measurements of backscattered ultraviolet radiation: theoretical basis, J. Geophys. Res., 103, 17099-17110, 1998.

Volz, F. E.: Infrared optical constants of ammonium sulfate, sahara dust, volcanic pumice, and flyash, Appl. Optics, 12, 564-568, 1973.

Zhang, P., Lu, N., Hu, X., and Dong, C.: Identification and physical retrieval of dust storm using three MODIS thermal IR channels, Global Planet. Change, 52, 197-206, 2006. 